Atmos. Chem. Phys., 18, 16775-16791, 2018

https://doi.org/10.5194/acp-18-16775-2018

(C) Author(s) 2018. This work is distributed under

the Creative Commons Attribution 4.0 License.

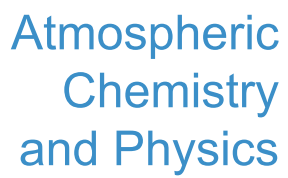

(c) (P)

\title{
Anomalous holiday precipitation over southern China
}

\author{
Jiahui Zhang ${ }^{1}$, Dao-Yi Gong ${ }^{1}$, Rui Mao ${ }^{1}$, Jing Yang ${ }^{1}$, Ziyin Zhang ${ }^{2}$, and Yun Qian ${ }^{3}$ \\ ${ }^{1}$ State Key Laboratory of Earth Surface Processes and Resource Ecology/Academy of Disaster Reduction and \\ Emergency Management, Faculty of Geographical Science, Beijing Normal University, Beijing, 100875, China \\ ${ }^{2}$ Institute of Urban Meteorology, Chinese Meteorological Administration, Beijing, 100089, China \\ ${ }^{3}$ Pacific Northwest National Laboratory, Washington 99352, USA
}

Correspondence: Dao-Yi Gong (gdy@bnu.edu.cn)

Received: 30 January 2018 - Discussion started: 2 May 2018

Revised: 12 October 2018 - Accepted: 1 November 2018 - Published: 28 November 2018

\begin{abstract}
The Chinese Spring Festival (CSF, also known as the Chinese New Year or Lunar New Year) is the most important festival in China. Lunar New Year's Day (LNYD) is the first day of the Lunar New Year. Traditionally, the CSF holiday begins a couple of days before LNYD and ends on lantern day, lasting for approximately 2 weeks. In this paper, based on the long-term station observations from 1979 to 2012 , the precipitation during the holiday over southern China (108-123 $\mathrm{E}$ and $21-33^{\circ} \mathrm{N}, 155$ stations) tends to be lower than that before and after the holiday. The mean precipitation frequency anomaly from the fourth day to the sixth day after LNYD (i.e., days $[+4,+6]$ ) decreases by $-7.4 \%$. Simultaneously, the daily precipitation amount experiences a reduction of $-0.62 \mathrm{~mm}_{\text {day }^{-1}}$ during days $[+2,+5]$. The holiday precipitation anomalies are strongly linked to the anomalies of relative humidity $(\Delta \mathrm{RH})$ and cloud cover. The station observations of the $\Delta \mathrm{RH}$ show an evident decrease from day +2 to day +7 , and a minimum appears on days $[+4,+6]$, with a mean of $-3.9 \%$. The $\Delta \mathrm{RH}$ vertical profile displays significant drying below approximately $800 \mathrm{hPa}$. Between 800 and $1000 \mathrm{hPa}$, the mean $\Delta \mathrm{RH}$ is $-3.9 \%$. The observed station daytime low cloud cover (LCC) evidently decreases by $-6.1 \%$ during days $[+4,+6]$. Meanwhile, the ERA-Interim daily LCC also shows a comparable reduction of $-5.0 \%$. The anomalous relative humidity is mainly caused by the decreased water vapor in the lower-middle troposphere. Evident negative specific humidity anomalies persist from day -3 to day +7 in the station observations. The average specific humidity anomaly for days $[+4,+6]$ is $-0.73 \mathrm{~g} \mathrm{~kg}^{-1}$. When the precipitation days are excluded, the anomaly remains significant at $-0.46 \mathrm{~g} \mathrm{~kg}^{-1}$. A significant water vapor deficit is observed in the lower troposphere be-
\end{abstract}

low $700 \mathrm{hPa}$. Between 800 and $1000 \mathrm{hPa}$, the mean specific humidity drops by $-0.70 \mathrm{~g} \mathrm{~kg}^{-1}$. This drier lower-middle troposphere is due to anomalous northerly winds, which are closely related to the cyclonic circulation anomaly over the northwestern Pacific. The time-lag correlation demonstrates that approximately 1 week after a lower temperature occurs over eastern China, a stronger cyclone is observed over the western Pacific. The possible mechanism needs further clarification through elaborate observation and numerical modeling.

\section{Introduction}

Human activities have important impacts on weather and climate at diverse spatiotemporal scales by causing changes in the amounts of greenhouse gases, aerosols, and cloudiness in the Earth's atmosphere. The changes in these factors alter the energy balance of the Earth-atmosphere system. In particular, the large uncertainty involving the clouds, precipitation, and radiation makes it difficult to accurately estimate the contributions of these factors to long-term climate changes (Boucher et al., 2013). Recent estimation indicates that in fast-developing China, anthropogenic emissions may have contributed $10 \% \pm 4 \%$ in the current global radiative forcing (B. Li et al., 2016). Many related studies have noted that short-term air pollution associated with intense economical, political, and cultural events has discernible influences on local and/or regional weather worldwide, where air pollution caused by regular or occasional anthropogenic emissions significantly impacts atmospheric physics and chemistry (e.g., Zhao et al., 2006; Sanchez-Lorenzo et al., 2012; Williams 
et al., 2015). The involved cloud-precipitation processes and interactions over monsoonal Asia remains the most challenging topic (Z. Li et al., 2016).

Alternating weekdays and weekends may be the most apparent regular activity of human beings. The so-called weekly cycle effects of atmospheric parameters, which are strongly related to the aforementioned regular human activity, have been widely reported globally (Gordon, 1994; Cerveny and Balling, 1998; Bäumer et al., 2008). At first, these studies of the weekly cycles were focused on cities and industrialized areas. Later, reportedly, the weekly cycles of atmospheric variables are not only local phenomena confined within urban areas but also large-scale phenomena that are closely related to regular human activities (Gordon, 1994). Over developed Europe, for example, Bäumer et al. (2008) analyzed the station data from the Aerosol Robotic Network over central Europe and reported that the aerosol optical thickness is higher midweek than on the weekend. In rapidly industrializing Asia, there are also discernible weekly cycles in meteorological parameters. For example, Gong et al. (2006) found that the weekend effect in the diurnal temperature range (DTR) has the opposite signal between winter and summer, where wintertime DTR tends to have a positive weekend effect (i.e., larger DTR on weekend days compared to weekdays), which is in association with increased maximum temperature and total irradiance but decreased relative humidity, whereas summertime DTR displays a much stronger and significantly negative weekend effect. Evident weekly cycles are also identified in other parameters, such as wind speed, precipitation frequency (Gong et al., 2007), and thunderstorm frequency (Yang et al., 2016). In South Korea, Kim et al. (2009) found that there is more cloudiness and less insolation for Wednesday-Thursday and less cloudiness and more insolation for Monday-Tuesday. Furthermore, weekly periodicities are enhanced, especially in autumn, more than 2-3 times as great as those of the annual mean with long-term surface measurements of meteorology (1975-2005). The mechanisms of these weekly cycles are not yet fully understood, though their strong covariations with human activities (e.g., air pollutants) are widely measured. Gong et al. (2006, 2007) supposed that the phases of weekly cycle may depend on the different climatological circumstances. Wang et al. (2012) emphasized that during the autumn, the semi-direct aerosol effects likely play a dominant role in the weekly cycle of cloud cover in southeastern China. Yang et al. (2016) proposed the importance of human emission types.

In addition, there are occasional, intense human activities (e.g., societal and cultural events) that also change atmospheric environments (particularly the air quality). For example, Xin et al. (2012) found that the concentrations of $\mathrm{PM}_{2.5}$ in the Beijing-Tianjin-Hebei area are reduced by approximately $50 \%$ with the implementation of emission controls during the 2008 Beijing summer Olympic Games. Similar actions were also implemented when China hosted the
2014 Asia-Pacific Economic Cooperation meeting and held the 2015 national military parade; as a result, the air quality is considerably improved over northern China (Chen et al., 2015; Wang et al., 2015; Xu et al., 2015, 2017; Wen et al., 2016). In contrast, setting off fireworks during holiday celebrations can produce severe air pollution around the world, such as the Fourth of July holiday in America (Carranza et al., 2001), the New Year's fireworks in Mainz (Drewnick et al., 2006), the Diwali festival in India (Singh et al., 2014), and the Chinese Spring Festival (CSF; Tang et al., 2016). The emissions may differ in magnitude and type among these events (Wang et al., 2007; Zhang et al., 2010; Tang et al., 2016). Compared with weekly cycles, the possible meteorological covariations in association with these occasional, intense events are less studied.

Notably, the CSF holiday occurs annually in JanuaryFebruary across the whole country and is the most important holiday in China. Moreover, the CSF is a cultural tradition that is directly related to the daily activity of human beings, particularly economic activities. Human emissions during the CSF holiday decrease evidently (Lin and McElroy, 2011; Gong et al., 2014). Some studies have tried to identify the possible covariations in atmospheric physics and weather anomalies accompanying these local and regional occasional societal and cultural events. Travis et al. (2002) noted a significant increase in DTR in the United States during the 3 days after 11 September 2001 when civil aviation planes were grounded. Gong et al. (2014) analyzed the temperature anomalies during the CSF holiday from 2001 to 2012 and found that there are significant negative anomalies of approximately $-0.81{ }^{\circ} \mathrm{C}$ in eastern China, wherein atmospheric feedbacks likely play a role in enhancing cooling.

The purpose of the present study is to investigate the possible changes in precipitation over southern China during the CSF holiday. The paper is organized as follows. The data and methods are presented in Sect. 2. The results, including the anomalous precipitation frequency and amount; the relevant changes in humidity, cloud cover, and temperature; and the anomalous atmospheric water vapor and circulation are described in Sect. 3. The possible relevance of these results to human activity is discussed in Sect. 4. Finally, a summary is presented in Sect. 5 .

\section{Data and methods}

\subsection{Data and study area}

The daily precipitation data analyzed in the present study are obtained from the China Meteorological Administration observation archives. The daily precipitation amounts as well as the precipitation types are recorded. There are six kinds of readings, namely (a) no precipitation; (b) trace precipitation (daily precipitation readings of less than the measurable $0.1 \mathrm{~mm}$ ); (c) precipitation from fog, frost, and dew; 
(d) precipitation from pure snow; (e) precipitation from snow and rain; and (f) precipitation from rainfall. Because the frequency of snowfall events is low in the warm area of southern China and the precipitation from fog and dew is considerably small (accounting for $0.14 \%$ of our data), in this study we considered only the precipitation amounts and ignored the precipitation types. This dataset consists of 917 stations, and the earliest observations start in the 1950s. Here, we confined our analysis period to 1979-2012, during which China experienced rapid development and immense amounts of air pollutant emissions. Since we aim to investigate the precipitation around the CSF holiday, in this study only the daily precipitation from January to February is employed. After excluding the 319 stations with missing values, we retained the 598 stations without missing data during 1979-2012.

Prior to this analysis, we determined the target area based on the precipitation climatology. Because the Chinese Lunar New Year occurs in January or February, here, we investigated the climatological means of the precipitation amount as well as the precipitation days based on the observations from 598 stations. As shown in Fig. 1a, in the boreal winter, the number of precipitation days is much greater in southern China than in northern China. A maximum of $>35$ days occurs between approximately $25-30^{\circ} \mathrm{N}$ and $102-115^{\circ} \mathrm{E}$, while the precipitation frequency north of $35^{\circ} \mathrm{N}$ is less than 15 days. Simultaneously, the major precipitation belt, with precipitation amount $>50 \mathrm{~mm}$, also appears over the southeast of mainland China, which is generally consistent with the spatial features of the frequency patterns (Fig. 1a). Although the number of precipitation days in the Sichuan Basin is high, the precipitation amounts are not as large. In addition, the Sichuan Basin has a unique climate due to its special basin topography. Therefore, we did not include the Sichuan Basin in our study area. In addition, for 319 stations north of $33^{\circ} \mathrm{N}$, the average precipitation days and amounts are 12.8 days and $9.9 \mathrm{~mm}$, respectively. It would be difficult to obtain a statistically meaningful signal in northern China due to a small precipitation frequency and amount. Finally, we confined our study area to $108-123^{\circ} \mathrm{E}$ and $21-$ $33^{\circ} \mathrm{N}$ (as indicated by the black dashed rectangle in Fig. 1). Within this area, there are 155 available meteorological stations. Among these stations, the minimum number of precipitation days (15.7 days) appears at the Zhumadian station $\left(33^{\circ} \mathrm{N}, 114^{\circ} \mathrm{E}\right)$, and the minimum precipitation amount $(15.3 \mathrm{~mm})$ appears at the Ankang station $\left(32^{\circ} \mathrm{N}, 109^{\circ} \mathrm{E}\right)$. Meanwhile, the maximum precipitation days (41.6 days) and maximum precipitation amount $(214.5 \mathrm{~mm})$ are found at $\mathrm{Wu}-$ gang $\left(26^{\circ} \mathrm{N}, 110^{\circ} \mathrm{E}\right)$ and Nanyue $\left(27^{\circ} \mathrm{N}, 112^{\circ} \mathrm{E}\right)$, respectively. On average, the precipitation frequencies and amounts during the period of 1979-2012 are 30.3 days and $124 \mathrm{~mm}$, respectively. In addition to the daily precipitation, we also analyzed other meteorological variables, including the mean temperature and relative humidity.

The atmospheric circulation and moisture in the troposphere are taken from the ERA-Interim reanalysis datasets
Table 1. The Lunar New Year days from 1979 to 2012.

\begin{tabular}{ll|cl}
\hline Year & Date & Year & Date \\
\hline 1979 & 28 January & 1996 & 19 February \\
1980 & 16 February & 1997 & 7 February \\
1981 & 5 February & 1998 & 28 January \\
1982 & 25 January & 1999 & 16 February \\
1983 & 13 February & 2000 & 5 February \\
1984 & 2 February & 2001 & 24 January \\
1985 & 20 February & 2002 & 12 February \\
1986 & 9 February & 2003 & 1 February \\
1987 & 29 January & 2004 & 22 January \\
1988 & 17 February & 2005 & 9 February \\
1989 & 6 February & 2006 & 29 January \\
1990 & 27 January & 2007 & 18 February \\
1991 & 15 February & 2008 & 7 February \\
1992 & 4 February & 2009 & 26 January \\
1993 & 23 January & 2010 & 14 February \\
1994 & 10 February & 2011 & 3 February \\
1995 & 31 January & 2012 & 23 January \\
\hline
\end{tabular}

(Dee et al., 2011), which have a $1.5^{\circ}$ spatial resolution and span the period of 1979-2012. We utilized surface parameters, such as the cloud cover and total column water vapor. In addition, the impacts of air temperature, relative humidity, and horizontal winds on pressure levels are also investigated. Only the data at step 0 for 00:00, 06:00, 12:00, and 18:00 UTC are obtained and subjected to analysis. Averaging these four times yields the daily mean.

\subsection{Analysis method}

We employed a temporal composite analysis to investigate the possible changes in the daily precipitation and the statistical significance. This analysis is carried out via the following steps. First, we identified all Lunar New Year days (LNYDs) from 1979 to 2012. As listed in Table 1, the LNYDs all fall within late January to mid-February. During our analysis period, the earliest LNYD is on 22 January, and the latest occurs on 20 February. These LNYDs are denoted as day 0. The day before and the day after the LNYD are denoted as day -1 and day +1 , respectively. Accordingly, 2 days before and after the LNYD are denoted as day -2 and day +2 and so on.

Second, we estimated the anomalies from the climate means. When dealing with continuous variables (such as the temperature, humidity, atmospheric circulation, and water vapor), we calculated the long-term means for each calendar day from 1 January to 28 February. Then, the means are subtracted from the daily observations to determine the corresponding anomalies. This process is the same as that used in Gong et al. (2014). In contrast to these continuous variables, precipitation occurs randomly. For a specific day such as day 0 , we counted the number of precipitation days $(N)$ during the entire data period from 1979 to 2012. Thus, the 

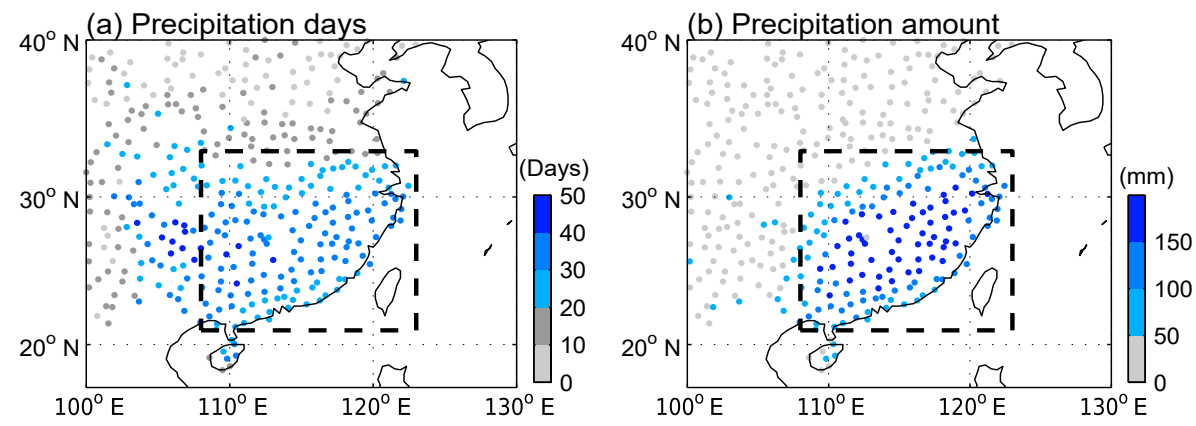

Figure 1. Spatial distribution of January-February precipitation days (a) and precipitation amount (b) for the period of 1979-2012. The study area is shown in a black dashed rectangle.

precipitation frequency (hereafter denoted as $F$ ) is deduced by

$F=\frac{N}{34} \times 100 \%$

To remove the randomness of precipitation, we used a 3-day window. For example, precipitation occurring on the previous day $($ day -1$)$ and the day after $($ day +1$)$ is considered to occur on day 0 . The above method is also used to calculate the climatic values of $F$, which are based on Gregorian calendar days. For a station from 1 January to 31 March, every day has a precipitation frequency. Then, with this climatic sequence, we used a 7-day window filter to reserve the changes for more than 7 days because the typical synoptic timescale is approximately 7 days. For a station, on a specific day, such as day 0 , all precipitation frequencies whose lunar dates are day 0 are found from the climatic sequence. Then, we calculated their average. The departure of $F$ from the average is the frequency anomaly $(\Delta F)$. The final result is the average of all stations' anomalies.

\section{Results}

\subsection{Significant reduction of precipitation}

We computed the daily anomalies of the precipitation frequencies for each station. To determine how the precipitation might change before and after LNYD, we considered days from -12 to +12 . This method is similar to that used by Gong et al. (2014). We also tried to use a longer time window and found that the conclusions remain the same. To focus on southern China, we computed the means for all 155 stations within the target area (Fig. 1). The regional mean $\Delta F$ is shown in Fig. 2a. Although the $\Delta F$ before the LNYD is generally positive, the salient feature is the $\Delta F$ reduction after the LNYD. The mean for day +3 to day +7 is $-5.5 \%$, and a minimum of $-9.4 \%$ occurs on day +5 . Note that the largest reductions occur on days $[+4,+6]$, where the averaged anomalies are as low as $-7.4 \%$. Precipitation is (a) Precipitation frequency
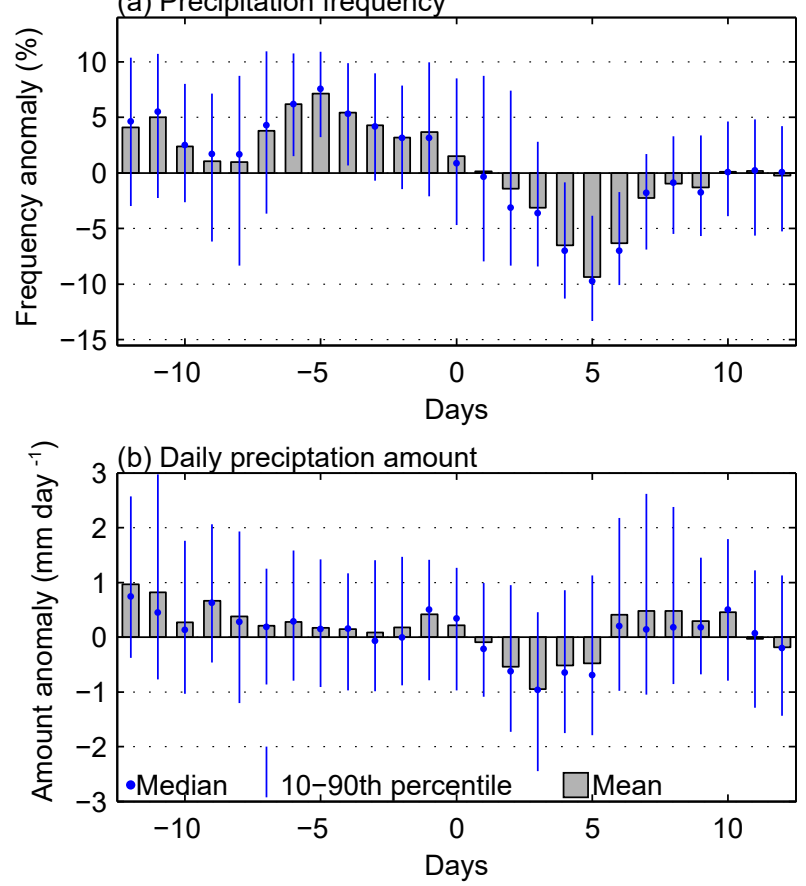

Figure 2. The anomalies of precipitation frequency (a) and amount (b) computed based on 155 stations. The means are shown as gray bars; and the median and the range of the 10th-90th percentiles are also plotted for comparison.

a natural phenomenon. Thus, its frequency anomaly should be spatiotemporally random for a certain day from 1979 to 2012 among all the stations over this large region. The standard deviation of the stations' $\Delta F$ would provide information concerning further uncertainties. A smaller standard deviation suggests that similar anomalies tend to be observed, thus indicating a robust signal, whereas a larger standard deviation implies diverse changes. We found that the standard deviation of days $[+3,+7]$ is approximately $\pm 3.7 \%$, which is smaller than the standard deviation of most days before the LNYD. Note that the means may be biased by 
outliers or skewness. Thus, to determine the diverseness of these frequency anomalies among the 155 stations, we also computed the medians and the lower and upper percentiles. In Fig. 2a, the ranges of the 10th and 90th percentiles are plotted as error bars and the medians are also shown. The 90th percentiles for the days $[+4,+6]$ are clearly $-0.9 \%$, $-3.9 \%$, and $-1.7 \%$, respectively, all being significantly below 0 . Simultaneously, the medians are generally similar to the means; for example, from day +3 to day +7 , the means $(-3.1 \%,-6.5 \%,-9.4 \%,-6.3 \%$, and $-2.2 \%$, respectively) and medians $(-3.6 \%,-7.0 \%,-9.8 \%,-7.0 \%$, and $-1.8 \%$, respectively) are almost identical, likely suggesting that the majority of the anomalies tend to be negative and that the means are not skewed by large departures or outliers.

We further investigated the statistical significance of the precipitation anomalies by employing a Monte Carlo approach (e.g., Stjern, 2011; Wang et al., 2012). Here, the Monte Carlo test is performed by randomly rearranging sequences of the lunar calendar days. For each experiment, we first generated the random sequence and then estimated the frequencies for each lunar day station by station. In addition, the regional anomaly mean is calculated as described above. We repeated these steps 1000 times and obtained the 10th and 90th percentiles of these experiments. By comparing the observations with these Monte Carlo-yielded percentiles, we may estimate whether the frequency anomalies are beyond those of random chance. If the original observations are lower than the 10th percentile, these measurements are significant at the 0.1 level.

For the regional mean frequency anomalies, there are few cases where the simulated anomaly is smaller than the observations during the holiday. Only 1 of 1000 random Monte Carlo experiments is below the observation on day +5 . On days +4 and +6 , there are 10 and 14 cases, respectively, with values smaller than the observation. On days +3 and +7 , there are slightly more values smaller than the observation (135 and 190, respectively). We found that the 10th percentiles during days +4 to +6 are $-3.6 \%,-3.4 \%$, and $-3.5 \%$, respectively. Note that the observations $(-6.5 \%$, $-9.4 \%$, and $-6.3 \%$ ) are all below the corresponding 10th percentiles of the Monte Carlo experiments. Therefore, we may conclude that the observed $\Delta F$ is significant at the 0.1 level from days +4 to day +6 . We also examined the medians of the 155 stations and found a similar result. For days $+4,+5$, and +6 , there are only 9,1 , and 7 cases, respectively, with values below the observations. The observed medians during days $+4,+5$, and +6 are $-7.0 \%,-9.8 \%$, and $-7.0 \%$, respectively, which are all below the Monte Carlo 10th percentiles $(-3.7 \%,-3.6 \%$, and $-3.6 \%$, respectively).

Further, we investigated the possible changes in daily precipitation amounts. Here, all trace precipitation records are excluded. The composite method is similar to that for frequency. In other words, for a specific lunar calendar day, the anomalous amount is calculated as the mean daily precipitation amount minus the climate reference, where the climate reference is estimated based on the Gregorian calendar. Then, we averaged the anomalies for all stations to obtain a regional mean. Figure $2 b$ shows the results. Interestingly, from day +2 to day +5 , the amounts experience continuously negative anomalies with a mean of $-0.62 \mathrm{~mm}_{\text {day }}{ }^{-1}$. In particular, a minimum of $-1.0 \mathrm{~mm} \mathrm{day}^{-1}$ occurs on day +3 . During days $+2,+4$, and +5 , the anomalies are similar (being $-0.54,0.52$, and $-0.48 \mathrm{~mm} \mathrm{day}^{-1}$, respectively). Differing from the precipitation frequency, the amounts ranging from the 10th to the 90th percentiles are obviously larger. In addition, during days $[+2,+5]$, the upper bounds all exceed zero and imply larger uncertainties. Thus, the gradual decrease in the amount after the LNYD is likely consistent with the significant reduction in precipitation frequency. Note that the Monte Carlo test suggests a high confidence of the negative amount anomalies during the holiday. Of 1000 Monte Carlo experiments, there are 83, 14, 75, and 70 cases with values smaller than the observations during days $[+2,+5]$. The Monte Carlo 10th percentiles for days $[+2,+5]$ are $-0.47,-0.45,-0.42$, and $-0.40 \mathrm{~mm} \mathrm{day}^{-1}$, respectively, whereas the corresponding observations of $-0.54,-0.95$, -0.52 , and $-0.48 \mathrm{mmday}^{-1}$ are all smaller. We also examined the median of the 155 stations by employing the Monte Carlo test. The results are similar. There are 70, 16, 66 , and 43 experimental values that are smaller than those observed. The medians of the observation for these days $\left(-0.63,-0.97,-0.65\right.$, and $-0.70 \mathrm{~mm} \mathrm{day}^{-1}$, respectively) are all smaller than the corresponding Monte Carlo 10th percentiles $(-0.56,-0.54,-0.52$, and -0.47 , respectively). Therefore, the means and medians of the amount anomalies during days $[+2,+5]$ are significant at the 0.1 level. Note that the large error bars in Fig. 2b may imply somewhat larger diversities or differences in the daily precipitation amounts among the 155 stations. The Monte Carlo test likely provides a more reasonable estimation of the significance. With the above analysis, we may conclude that there is a significant reduction in the precipitation frequency and a decrease in the daily precipitation amount after the LNYD.

\subsection{Spatial distribution of the holiday precipitation anomalies}

Although the precipitation reduction after the LNYD is evident in the composite analysis based on the regional means (Fig. 2), this feature might differ among stations. In this subsection, we investigated the spatial distribution of the precipitation anomalies. A significant frequency reduction occurs on days $[+4,+6]$, and a significant amount reduction appears on days $[+2,+5]$. Here, we computed the mean frequency anomalies during days $[+4,+6]$ and the mean amount anomalies during days $[+2,+5]$ for each station. The statistical significance is also estimated using the Monte Carlo test at each station. The method used is similar to that 

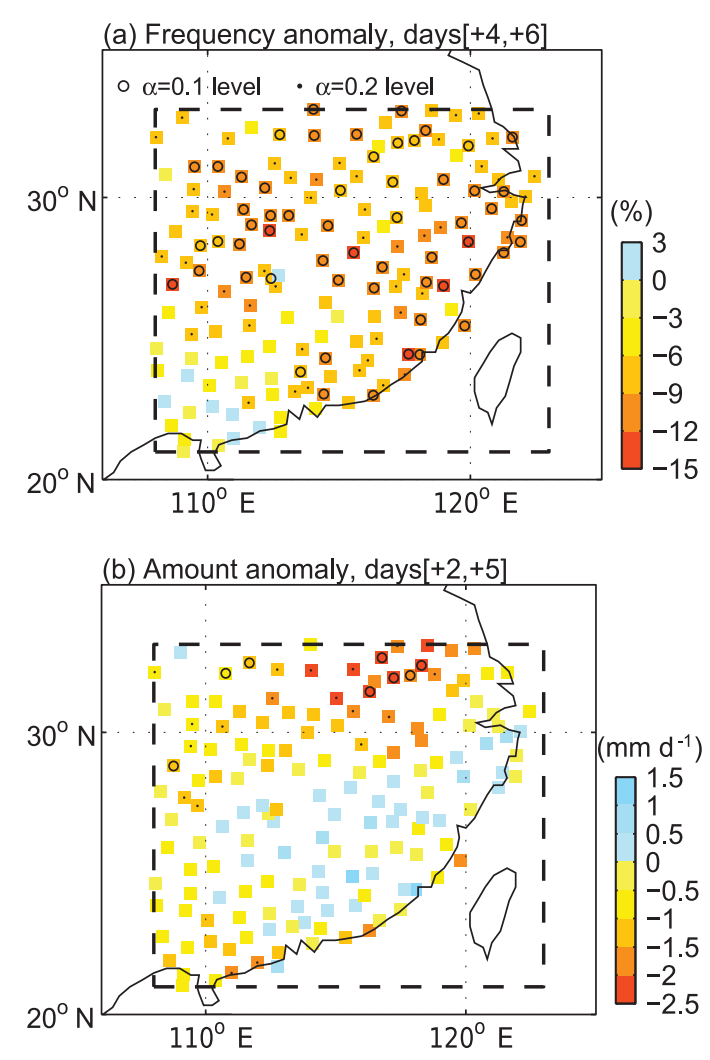

Figure 3. Anomalies of the precipitation frequency (a) and amount (b). The significance values are estimated using a Monte Carlo approach; stations with circles and dots denote that all days have values significant at the 0.1 and 0.2 levels, respectively.

described in Sect. 3.1. Here, the Monte Carlo test is performed for every station by randomly rearranging the lunar calendar, and the simulation is repeated 1000 times. The 10th (90th) and 20th (80th) percentiles are taken as the criteria. For the precipitation frequency, the mean value is regarded as significant at the 0.1 (or the 0.2 ) level only when the anomalies in all 3 days (i.e., days $+4,+5$, and +6 ) are significant at the 0.1 (or 0.2) level. Similarly, when the daily precipitation amounts on all four individual days (from day +2 to day +5 ) are significant, their mean is regarded as a significant anomaly. The results are shown in Fig. 3.

Figure 3a shows that the majority of the $\Delta F$ have negative signs. Among the 155 stations, only 7 stations have positive signs, and none of these positive anomalies are significant. Of the 148 stations with $\Delta F$ reductions, 57 stations are significant at the 0.1 level, and 108 are significant at the 0.2 level. Most stations located in the north and east of the study area have a significant $\Delta F$ reduction. The $\Delta F$ minimum reaches $-13.5 \%$ at the Sansui station $\left(27^{\circ} \mathrm{N}, 108^{\circ} \mathrm{E}\right)$. Considering the magnitude of the anomaly, there are 55 stations with $\Delta F$ reductions exceeding $-9 \%$. Among these 55 stations, the anomalies for 45 stations are significant at the
0.1 level, and those at the other 10 stations are significant at the 0.2 level.

Unlike the frequency, the spatial features of the amount anomalies differ among stations (Fig. 3b), which is consistent with the relatively larger span of the 10th-90th percentiles, as shown in Fig. 2b. Nevertheless, there are still 117 stations with decreased amounts during days $[+2,+5]$. Among these stations, 27 show significant decreases at the 0.2 level, and 8 stations show significant decreases at the 0.1 level. The largest reduction is $-2.41 \mathrm{~mm} \mathrm{day}^{-1}$, which appears at the Shouxian station $\left(32^{\circ} \mathrm{N}, 116^{\circ} \mathrm{E}\right)$.

Based on the above analysis of the temporal composites and spatial distributions, we found that significant reductions of precipitation frequency and daily precipitation amount occur regionally within an approximate 1 week period after the LNYD.

\subsection{Relative humidity and cloud anomalies}

Relative humidity ( $\mathrm{RH})$ is the most important factor that directly controls or influences precipitation. In this subsection, we investigated the possible changes in the relative humidity associated with the holiday precipitation decreases. Here, we examined the station data to analyze the relative humidity by making composites. Note that the method of estimating the anomalies is different from that for precipitation frequencies. The composites of the relative humidity (as well as those of other meteorological parameters analyzed in the following sections) are based on anomalies $(\Delta \mathrm{RH})$, which are obtained by subtracting the 1979-2012 long-term mean from the daily relative humidity values.

For each lunar calendar day, all 34 daily anomalies are collected and subjected to a $t$ test with the null hypothesis of their mean being not significantly different from zero at the 0.05 (or 0.1) level. In Fig. 4, we plotted the means during days $[-12,+12]$. To facilitate a comparison, the range of 1 standard error estimated from the 34 anomalies is shown via error bars. The $\Delta \mathrm{RH}$ experiences an evident decrease from day +2 to +7 , with a mean value of $-2.5 \%$. The driest value is $-4.6 \%$ at day +5 . The mean $\Delta \mathrm{RH}$ of the lowest anomalies for days $[+4,+6]$ is $-3.9 \%$, which is significant at the 0.1 level as estimated from a left-tail $t$ test. Note that the drying (wetting) may be the result of less (more) precipitation, as demonstrated in the previous sections. For clarity, we also computed the $\Delta \mathrm{RH}$ using only the data from no-rain days. We found that the $\Delta \mathrm{RH}$ for no-rain cases shows a similar temporal feature (figure not shown). The lowest values still occur on days $[+4,+6]$, with anomalies of $-0.97 \%,-0.69 \%$, and $-0.38 \%$, respectively. However, these anomalies are not statistically significant. This result could be caused by the relatively smaller data sample and exclusion of the precipitation days. The sample number of no-rain days is $48.9 \%$ of all days. In any case, the similar drying features on no-rain days may provide support for the 

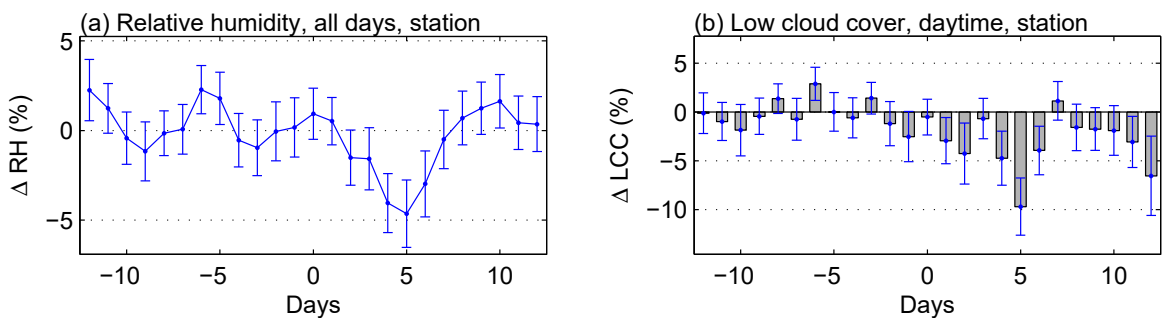

(c) Relative humidity, ERA-Interim, $850 \mathrm{hPa}$

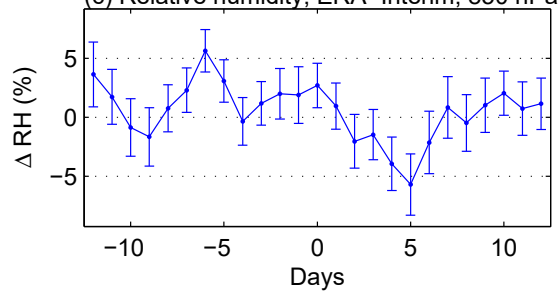

(d) Low cloud cover, daily, ERA-Interim

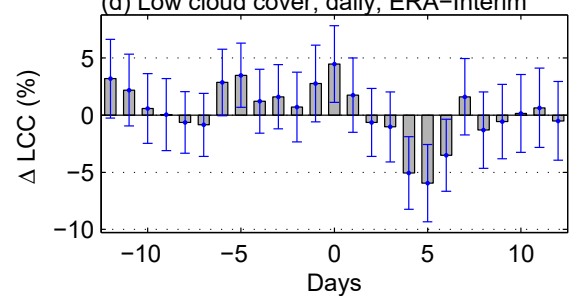

Figure 4. Station observational relative humidity anomalies $(\triangle \mathrm{RH})$ estimated from all available days (a) and the daytime low cloud cover (LCC) anomalies (b) during the holiday from 1979 to 2012. ERA-Interim $\Delta \mathrm{RH}$ at $850 \mathrm{hPa}$ (c) and the daily LCC anomalies (d) during the holiday. Standard error is shown as error bars.
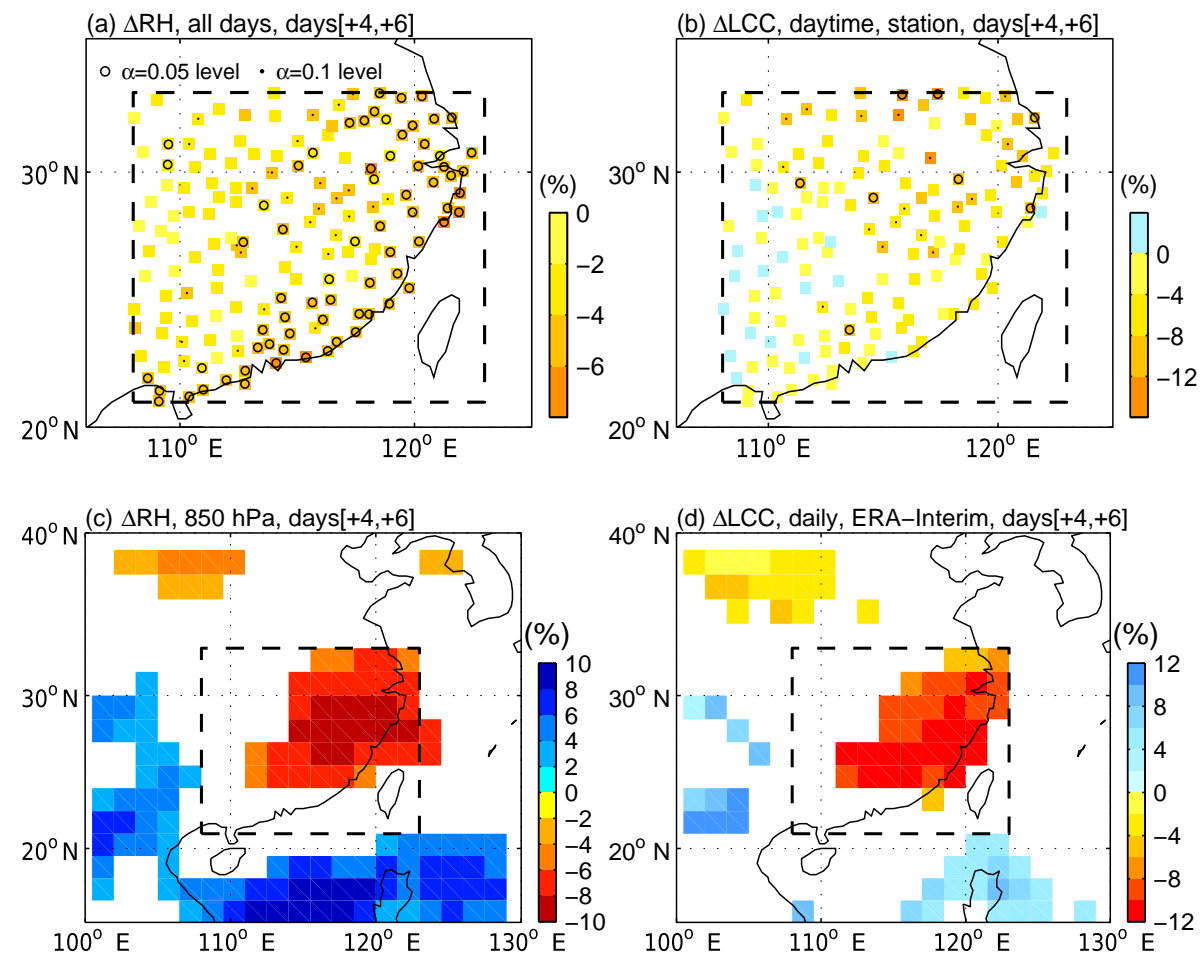

Figure 5. Station anomalies of relative humidity (RH) estimated from all available days (a) and daytime low cloud cover (b) during days +4 to +6 . The significance is estimated using a $t$ test; stations with circles and dots denote values are significant at the 0.05 and 0.1 levels, respectively. Spatial distribution of ERA-Interim $\Delta \mathrm{RH}$ at $850 \mathrm{hPa}$ (c) and the daily LCC anomalies (d) during days +4 to +6 . Only the significant values (at the 0.1 level) are plotted.

theory that the lower $\Delta \mathrm{RH}$ could be a cause of the precipitation reduction and may even help enhance the drying.

We also examined the spatial distribution of the $\Delta R H$. The station means of the $\Delta \mathrm{RH}$ during days $[+4,+6]$ are plotted in Fig. 5. All 155 stations show negative anomalies, with a maximum and a minimum of $-0.6 \%$ and $-8.1 \%$, respectively. When estimating the statistical significance, we considered the mean for days $[+4,+6]$. Thus, we did not consider the significance of each of the 3 days. If the resulting anomaly is significant at the 0.05 (or 0.1 ) level as calculated 
by a $t$ test, this station is regarded as significant during days $[+4,+6]$. As shown in Fig. 5, there are $70(98)$ stations that are significant at the $0.05(0.1)$ level. Additionally, we investigated the spatial features of no-rain days and found that most $\Delta \mathrm{RH}$ values during days $[+4,+6]$ are also negative (the number of stations is 136 , accounting for approximately $88 \%$ of the total stations), and the lowest anomaly is $-7.6 \%$ (figure not shown). Again, this result suggests a drying atmosphere near the surface during the New Year holiday.

For the stratus precipitation during the winter season, the relative humidity in the lower-middle troposphere is more important than the surface humidity. The precipitation reduction could occur with a drier and upper atmosphere. Then, we investigated the $\triangle \mathrm{RH}$ in the lower-middle troposphere using the ERA-Interim reanalysis datasets of the pressure levels from 1979 to 2012. Here, we selected 99 grid points between $21-33^{\circ} \mathrm{N}$ and $108-123^{\circ} \mathrm{E}$. We examined the $\Delta \mathrm{RH}$ values at each level from 1000 to $500 \mathrm{hPa}$. Generally, the results are similar, showing drying tendencies throughout as expected. Note that the $\triangle \mathrm{RH}$ values in the low levels are more evident. At $1000 \mathrm{hPa}$, the $\Delta \mathrm{RH}$ shows a continuous reduction during days $[+3,+6]$, with a mean decrease of $-3.8 \%$. The negative anomalies on these days are significant at the 0.1 level. The largest reduction occurs on day +5 , being $-5.2 \%$ (figure not shown). In Fig. 4, we plotted the regional mean $\Delta \mathrm{RH}$ at $850 \mathrm{hPa}$. A similar reduction is observed during days $[+2$, $+6]$, where the lowest anomalies are still found on days $[+4$, $+6]$. In addition, the values on days +4 and $+5(-4.0 \%$ and $-5.7 \%$ ) are both significant at the 0.1 level. In the middleupper troposphere, the $\Delta \mathrm{RH}$ during the holiday is not evident.

The spatial distributions of $\triangle \mathrm{RH}$ at 1000 and $850 \mathrm{hPa}$ during days $[+4,+6]$ are also analyzed. At $1000 \mathrm{hPa}$, the majority of the significantly negative $\Delta \mathrm{RH}$ values are located over southern China and the neighboring western Pacific, with a northeast-southwest distribution. The results at $850 \mathrm{hPa}$ are plotted in Fig. 5, and only the significant values (above the 0.1 level) are shown. At $850 \mathrm{hPa}$, the significant region is spatially smaller but has a greater magnitude than that at $1000 \mathrm{hPa}$. Over the land, the majority of the anomalies are between $-4 \%$ and $-6 \%$ at $1000 \mathrm{hPa}$, whereas the values are between $-6 \%$ and $-10 \%$ at $850 \mathrm{hPa}$. The minimum grid point value at $1000 \mathrm{hPa}$ is $-6.5 \%$, while the minimum is as low as $-9.7 \%$ at $850 \mathrm{hPa}$.

The drying in the lower troposphere can be more clearly seen in the relative humidity profiles. The vertical profile of the $\Delta \mathrm{RH}$ during days +4 to +6 , as averaged over all 99 grids in southern China, is shown in Fig. 6. Because the meaningful changes occurred in the lower troposphere, here we only plotted the $\Delta \mathrm{RH}$ values below the $500 \mathrm{hPa}$ level. Below $500 \mathrm{hPa}$, the anomalies all have negative signs. In addition, the significant $\triangle \mathrm{RH}$ values appear below the approximately $800 \mathrm{hPa}$ level (Fig. 6a). The negative anomaly at $850 \mathrm{hPa}$ is $-3.9 \%$, and that at $1000 \mathrm{hPa}$ is $-4.2 \%$. The mean for these layers (below $800 \mathrm{hPa}$ ) is $-3.9 \%$. Generally, the significant drying of the relative humidity appears in the lower-middle troposphere, which physically agrees with the precipitation reduction.

As the relative humidity at the lower-middle level decreases, consistent changes in clouds should occur, particularly in the low cloud cover (LCC). To confirm this, we first analyzed the surface-observed cloud data, which are from the Global Surface Weather Dataset obtained from the China Meteorological Administration. In this dataset, the observations are taken four times per day (00:00, 06:00, 12:00, 18:00 UTC) during the years 1980-2012, except during 2000, which is not available. Only those days with all four records are included. Of the 304 stations in our study area, we selected 137 stations with overall data availabilities above $30 \%$. When deriving the anomalies, we applied the same method as that used for $\Delta \mathrm{RH}$. The results show that both the total cloud cover and LCC reduce, the LCC especially experiences a significant decrease during the New Year holiday. It seems the reduction of total cloud cover is contributed to by the decrease in LCC. The mean anomaly of LCC during days $[+1,+5]$ is $-2.6 \%$. In addition, a minimum of $-3.1 \%$ appears on day +5 , which is significant at the 0.1 level. We should note that sometimes the LCC cannot be completely distinguished from the middle cloud cover in the station observations. Moreover, the cloud cover changes rapidly and might depend on the observer. At nighttime, the uncertainty in the observations is much greater. We would expect more reliable observations during the daytime. The mean LCC of 00:00 and 06:00 UTC is computed and regarded as the daytime observation. As shown in Fig. 4b, the daytime LCC shows an evident reduction during days $[+4,+6]$. The values of the 3 days are each significant at the 0.1 level, as estimated using a left-tail $t$ test. The mean for the 3 days is $-6.1 \%$, and a minimum of $-9.7 \%$ occurs on day +5 . Compared to the climate daytime cloud cover of $78 \%$ during January to March in southern China, the LCC reduction during the New Year holiday has a considerably large magnitude. Figure $5 \mathrm{~b}$ shows the spatial distribution of the daytime LCC values during days $[+4,+6]$. For a total of 137 stations, $119(86.9 \%)$ stations show negative signs. In addition, there are 8 (27) stations with values significant at the $0.05(0.1)$ level, as estimated via a both-tail $t$ test. A minimum of $-16.8 \%$ occurs at the Fuyang station $\left(33^{\circ} \mathrm{N}\right.$, $\left.115^{\circ} \mathrm{E}\right)$.

To assess the robustness of the cloud cover changes, the ERA-Interim data about cloud cover are investigated. We found that the high cloud cover and middle cloud cover show no significant changes (figure not shown). Interestingly, there is a significant reduction in the LCC during the CSF holiday. Figure $4 \mathrm{~d}$ shows the temporal variations in the ERA-Interim LCC. The LCC clearly shows an outstanding reduction during days $[+4,+6]$. The largest reduction, i.e., $-5.9 \%$, appears on day +5 . The values from day +4 to day +5 are all significant at the 0.1 level, as calculated by a left-tail $t$ test. Averaging over days $[+4,+6]$, the mean value is $-5.0 \%$. 

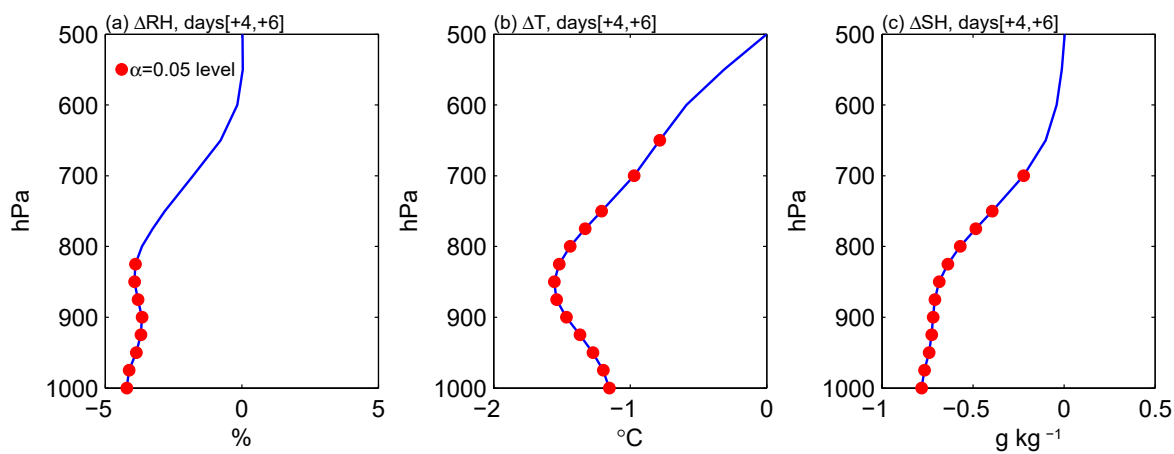

Figure 6. The vertical profiles of the relative humidity (a), temperature (b), and specific humidity (c) anomalies below $500 \mathrm{hPa}$. The significance level is estimated using a left-tail $t$ test, and the values significant at the 0.05 level are indicated with red dots.

This magnitude is comparable to the station-based daytime LCC anomaly ( $-6.1 \%)$. The spatial distribution of the LCC anomalies for the ERA-Interim data during days $[+4,+6]$ is shown in Fig. 5d. The LCC reduction center is located in the eastern region and has a magnitude between approximately $-8 \%$ and $-12 \%$. This reduction is almost identical to that of the station observations (cf., Fig. 5b, d). Note that in the ERA-Interim data, the cloud height is defined according to the corresponding sigma level. The low clouds correspond to sigma 0.8-1.0. A significant decrease in the relative humidity occurs below $800 \mathrm{hPa}$ (Fig. 6a), which physically agrees with the negative LCC anomalies.

\subsection{Temperature and water vapor anomalies}

The negative $\Delta \mathrm{RH}$ during the holiday might be caused by anomalous temperatures, the water vapor, or both, depending on certain conditions. In this subsection, we analyzed the changes in the temperature and water vapor associated with the holiday precipitation reduction. First, we examined the temporal changes in the temperature over southern China using the same composite analysis as that used for the relative humidity. We found that there is continuous cooling of the daily mean temperatures from day -3 to day +6 , which are all significant at the 0.1 level, as estimated by a left-tail $t$ test (figure not shown). The mean temperature anomaly of these days is $-1.12^{\circ} \mathrm{C}$. The maximum and minimum temperature anomalies are -0.70 and $-1.42^{\circ} \mathrm{C}$ for days +6 and +3 , respectively. Precipitation often causes a low temperature. To exclude the possible influence of precipitation on temperature, we also examined the daily temperatures for no-rain days and found a similar temperature anomaly of $-1.22{ }^{\circ} \mathrm{C}$ for days +1 to +6 . In addition, there is a similar minimum of $-1.48^{\circ} \mathrm{C}$. These values for the no-rain days are significant at the 0.05 level.

Note that Gong et al. (2014) reported negative temperature anomalies over the whole of eastern China around the LNYD when analyzing the shorter data period of 2001-2012. They found that the most significant decreases appear on days -3 to +2 , with a mean value of $-0.81{ }^{\circ} \mathrm{C}$. However, the temperature beyond this period over southern China is not addressed in their analysis. As demonstrated in the previous sections, the most significant reductions of the $\Delta F$ and $\Delta \mathrm{RH}$ are observed on days $[+4,+6]$. Thus, we further computed the mean of the temperature anomalies $(\Delta T)$ for days $[+4$, $+6]$ and estimated their statistical significance using a $t$ test for each of the stations. The results show that all 155 stations have negative anomalies (figure not shown). The maximum $\Delta T$ of $-0.28^{\circ} \mathrm{C}$ occurs at the Fengjie station $\left(31^{\circ} \mathrm{N}\right.$, $109^{\circ} \mathrm{E}$ ), and a minimum of $-2.14^{\circ} \mathrm{C}$ appears at the Jiuxian station $\left(25^{\circ} \mathrm{N}, 118^{\circ} \mathrm{E}\right)$. The anomalies for 116 stations are statistically significant at the 0.1 level, and those for 95 stations are significant at the 0.05 level. We also investigated the temperature anomalies during days $[+4,+6]$ using norain days and found similar results. All stations continue to show negative anomalies, and more stations are significant (134 stations exceed the 0.1 level, and 117 stations exceed the 0.05 level).

The above spatial distribution suggests that temperature anomalies are unlikely at the local scale. For clarity, we also investigated the vertical profiles and the spatial distributions of $\Delta T$ using the ERA-Interim pressure level data. The mean $\Delta T$ values below the $500 \mathrm{hPa}$ level during days $[+4,+6]$ are averaged for all 99 grid points over southern China and plotted in Fig. 6b. The significant negative temperature anomalies below $700 \mathrm{hPa}$ are evident, where all values are as low as $<-1{ }^{\circ} \mathrm{C}$. The mean for these layers is $-1.37^{\circ} \mathrm{C}$. To determine whether the cooling of the lower-middle troposphere is a regional-scale phenomenon, we further analyzed the spatial distribution of $\Delta T$. Note that the minimum of $-1.56^{\circ} \mathrm{C}$ occurs at the $850 \mathrm{hPa}$ level in Fig. 6b. Here, we computed the $850 \mathrm{hPa} \Delta T$ during days $[+4,+6]$ for each of the grid points (figure not shown), revealing that the majority of the study area experiences significant cooling (exceeding $-1{ }^{\circ} \mathrm{C}$ ) that is almost identical to that from the surface station observations. Based on these analyses, we may conclude that during the holiday (particularly days $[+4,+6]$ ), there is an anoma- 

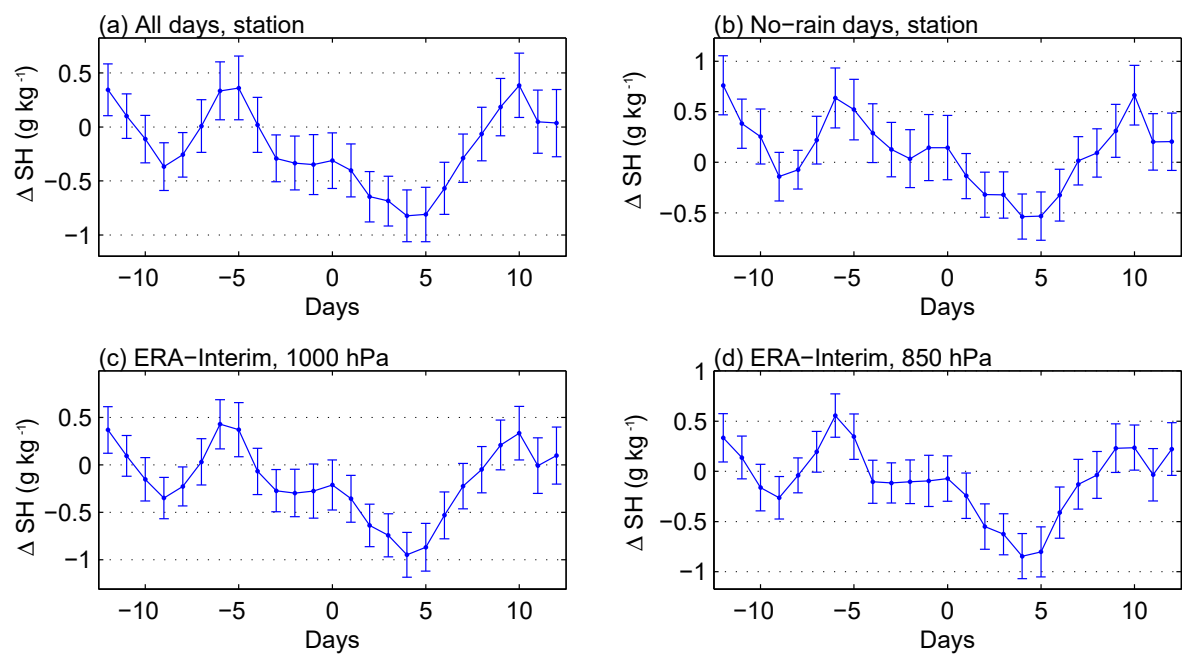

Figure 7. Means of station-specific humidity anomalies $(\Delta \mathrm{SH})$ during the holiday from 1979 to 2012 as estimated from all available days (a) and no-rain days (b). The corresponding ERA-Interim $\Delta \mathrm{SH}$ at $1000 \mathrm{hPa}(\mathbf{c})$ and $850 \mathrm{hPa}(\mathbf{d})$ are also plotted.

lous temperature cooling over southern China from the surface to the middle troposphere (below $500 \mathrm{hPa}$ ).

Cooling favors condensation and precipitation. If the water vapor content remains constant, a cooler temperature should result in a higher $\Delta \mathrm{RH}$. During the period of 1979-2012, over southern China, the climatic mean temperatures for days $[+4,+6]$ at 1000 and $850 \mathrm{hPa}$ are 9.3 and $3.3^{\circ} \mathrm{C}$, respectively. Meanwhile, the specific humidities at 1000 and $850 \mathrm{hPa}$ are 5.5 and $4.4 \mathrm{~g} \mathrm{~kg}^{-1}$, respectively. According to the Clausius-Clapeyron equation (Murray, 1967), the climatological relative humidities are $75.4 \%$ at $1000 \mathrm{hPa}$ and $77.5 \%$ at $850 \mathrm{hPa}$. The observed cooling of $-1.15^{\circ} \mathrm{C}$ at $1000 \mathrm{hPa}$ and $-1.56^{\circ} \mathrm{C}$ at $850 \mathrm{hPa}$ (Fig. 6b) could result in corresponding $\triangle \mathrm{RH}$ increases of $+6.0 \%$ and $+9.1 \%$, respectively. This contradicts the observed negative $\Delta \mathrm{RH}$ anomalies (cf., Fig. 5). Therefore, the cooling temperature is not a direct factor causing the drier $\Delta \mathrm{RH}$ and the precipitation reduction.

Alternatively, the water vapor should be responsible for the anomalous $\Delta \mathrm{RH}$. We analyzed the station specific humidity $(\mathrm{SH})$. Here, the $\mathrm{SH}$ is estimated from the surface pressure, relative humidity, and temperature, where the Tetens formula is employed to estimate the saturated vapor pressure over water (Murray, 1967). Figure 7a shows the specific humidity anomalies $(\Delta \mathrm{SH})$ before and after the LNYD. Evident negative anomalies persist from days -3 to +7 . The lowest values appear at days $[+4,+5]$ approximately. Note that the negative $\Delta \mathrm{SHs}$ during days +2 to +6 are significant at the 0.05 level, with a mean of $-0.71 \mathrm{~g} \mathrm{~kg}^{-1}$. A minimum of $-0.82 \mathrm{~g} \mathrm{~kg}^{-1}$ occurs on day +4 . In addition, the average $\Delta \mathrm{SH}$ for days $[+4,+6]$ is $-0.73 \mathrm{~g} \mathrm{~kg}^{-1}$. We repeated the composite analyses for no-rain days and found that the $\Delta \mathrm{SH}$ has a similar continuous reduction after LNYD (Fig. 7b). The $\Delta$ SHs of days $[+2,+5]$ are significant at the 0.1 level, and their mean is $-0.43 \mathrm{~g} \mathrm{~kg}^{-1}$. The minimum of $-0.54 \mathrm{~g} \mathrm{~kg}^{-1}$ also appears on day +4 , while the mean from day +4 to +6 is $-0.46 \mathrm{~g} \mathrm{~kg}^{-1}$, being smaller than the values estimated for all days. Simultaneously, the spatial distribution of $\Delta \mathrm{SH}$ during days $[+4,+6]$ reveals a regional-scale reduction over the study area (Fig. 8). All stations clearly show negative anomalies, both when all days are analyzed and when only no-rain days are analyzed. In the former instance, the $\Delta \mathrm{SH}$ values for the 140 stations are statistically significant at the 0.05 level, and in the latter case the number of stations with statistically significant values is 102 .

Further, we investigated the $\Delta \mathrm{SH}$ values in the lowermiddle troposphere using the ERA-Interim reanalysis data. The $\Delta \mathrm{SH}$ at $1000 \mathrm{hPa}(850 \mathrm{hPa})$ during days $[+2,+6]$ are all significant at the $0.05(0.1)$ level, with a mean of -0.75 $(-0.65) \mathrm{g} \mathrm{kg}^{-1}$. It is clear that the $\Delta \mathrm{SHs}$ at 1000 and $850 \mathrm{hPa}$ display features similar to those of the surface observations in both temporal variations and magnitudes of negative anomalies during the holiday (cf., Fig. 7). Furthermore, we investigated the spatial distributions of $\Delta \mathrm{SH}$ on days $[+4,+6]$. The evident $\Delta \mathrm{SH}$ reduction covers nearly all of southern China, with minimums extending from southeastern China to the western North Pacific, south of approximately $30^{\circ} \mathrm{N}$ (Fig. 8). The anomaly center lies between $110-130^{\circ} \mathrm{E}$ and $20-30^{\circ} \mathrm{N}$.

The drying of the $\Delta \mathrm{SH}$ in the lower-middle troposphere is more obvious, as seen in the vertical profile (Fig. 6c). Significant negative $\Delta \mathrm{SH}$ values appear below $700 \mathrm{hPa}$. Below $800 \mathrm{hPa}$, the $\Delta \mathrm{SH}$ values are all less than $-0.50 \mathrm{~g} \mathrm{~kg}^{-1}$. The mean for these layers ( 800 to $1000 \mathrm{hPa}$ ) is $-0.70 \mathrm{~g} \mathrm{~kg}^{-1}$. Similarly, we also estimated the variations of the relative humidity corresponding to these $\Delta \mathrm{SHs}$. The $\Delta \mathrm{SHs}$ at 1000 and $850 \mathrm{hPa}$ are -0.78 and $-0.69 \mathrm{~g} \mathrm{~kg}^{-1}$, respectively (Fig. 6c). If the temperature remains unchanged, these values would reduce the relative humidity by $-10.9 \%$ and $-12.3 \%$, 

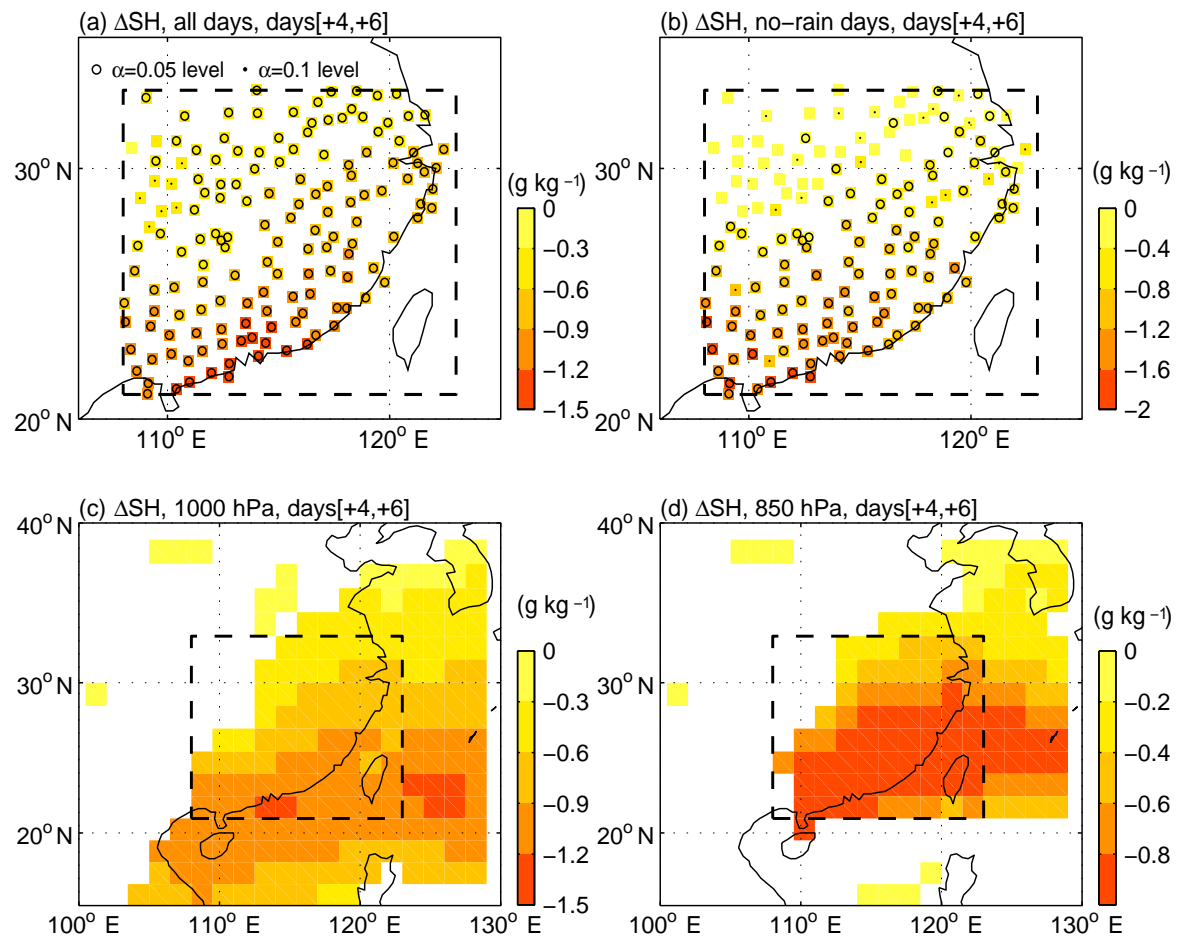

Figure 8. Spatial distribution of the observational specific humidity anomalies $(\Delta \mathrm{SH})$ during days $[+4,+6]$ as estimated from all available days (a) and no-rain days (b). The spatial distributions of the ERA-Interim $\Delta \mathrm{SH}$ at $1000 \mathrm{hPa}(\mathbf{c})$ and $850 \mathrm{hPa}(\mathbf{d})$ during days [+4, +6]. Only the significant values (above the 0.05 level) are plotted.

respectively. Obviously, the water vapor reduction in the lower-middle troposphere plays the dominant role in causing anomalous relative humidity, low-level cloud, and precipitation.

The total column water vapor (TCWV), or the precipitable water, is also a large-scale factor that correlates well with precipitation (e.g., Qian et al., 2009). The drying from the surface to the mid-troposphere is suggestive of the reduction in the TCWV. For clarification, we performed a composite analysis of the ERA-Interim TCWV. Unsurprisingly, the $\triangle \mathrm{TCWV}$ experiences a continuous reduction from day +1 to day +5 (Fig. 9a). The $\triangle \mathrm{TCWV}$ are significant at the 0.05 level during days $[+2,+5]$, with a mean of $-1.93 \mathrm{~kg} \mathrm{~m}^{-2}$. In addition, the largest negative $\triangle \mathrm{TCWV}$ values are observed on days +4 and +5 (2.43 and $2.36 \mathrm{~kg} \mathrm{~m}^{-2}$, respectively). The spatial distribution of the $\triangle \mathrm{TCWV}$ values during days $[+4,+6]$ is shown in Fig. 9b. The TCWV decreases by approximately $-1.00 \mathrm{~kg} \mathrm{~m}^{-2}$ or more over most of southern China. The minimum is located over the neighboring western North Pacific between $120-130^{\circ} \mathrm{E}$ and $20-30^{\circ} \mathrm{N}$. Meanwhile, positive $\triangle \mathrm{TCWV}$ s with somewhat smaller magnitudes appear to the east (over approximately $150-175^{\circ} \mathrm{E}$ and $20-30^{\circ} \mathrm{N}$ ). Generally, the reduction in the TCWV over the western North Pacific and eastern China is physically consistent with the negative anomalies of SH over southern
China. The observed decrease in precipitable water during the holiday is unfavorable for precipitation.

Based on the above analysis, we may conclude that, although the relative humidity (as well as the relevant cloud cover and precipitation) would benefit from the cooling temperatures, its reduction during days $[+4,+6]$ is strongly dominated by the drying water vapor in the lower troposphere. Therefore, the reduction of SH is likely to contribute to the decrease in precipitation during the New Year holiday.

\subsection{Water vapor budget and atmospheric circulation}

Our analysis demonstrates that in association with the significant precipitation reduction over southern China, an anomalous negative departure of the SH occurs. One further question is what causes such water vapor deficits during the New Year holiday? Here, we discussed the possible factors relevant to the atmospheric column water vapor balance as well as their individual contributions. Regional changes in the column water vapor are essentially related to two components. One is the budget between evaporation and precipitation, and the other is the budget of moisture inflow and outflow from the horizontal air motion crossing the four lateral boundaries. We investigated the corresponding anomalies separately during the holiday. 
(a) Total column water vapor, ERA-Interim
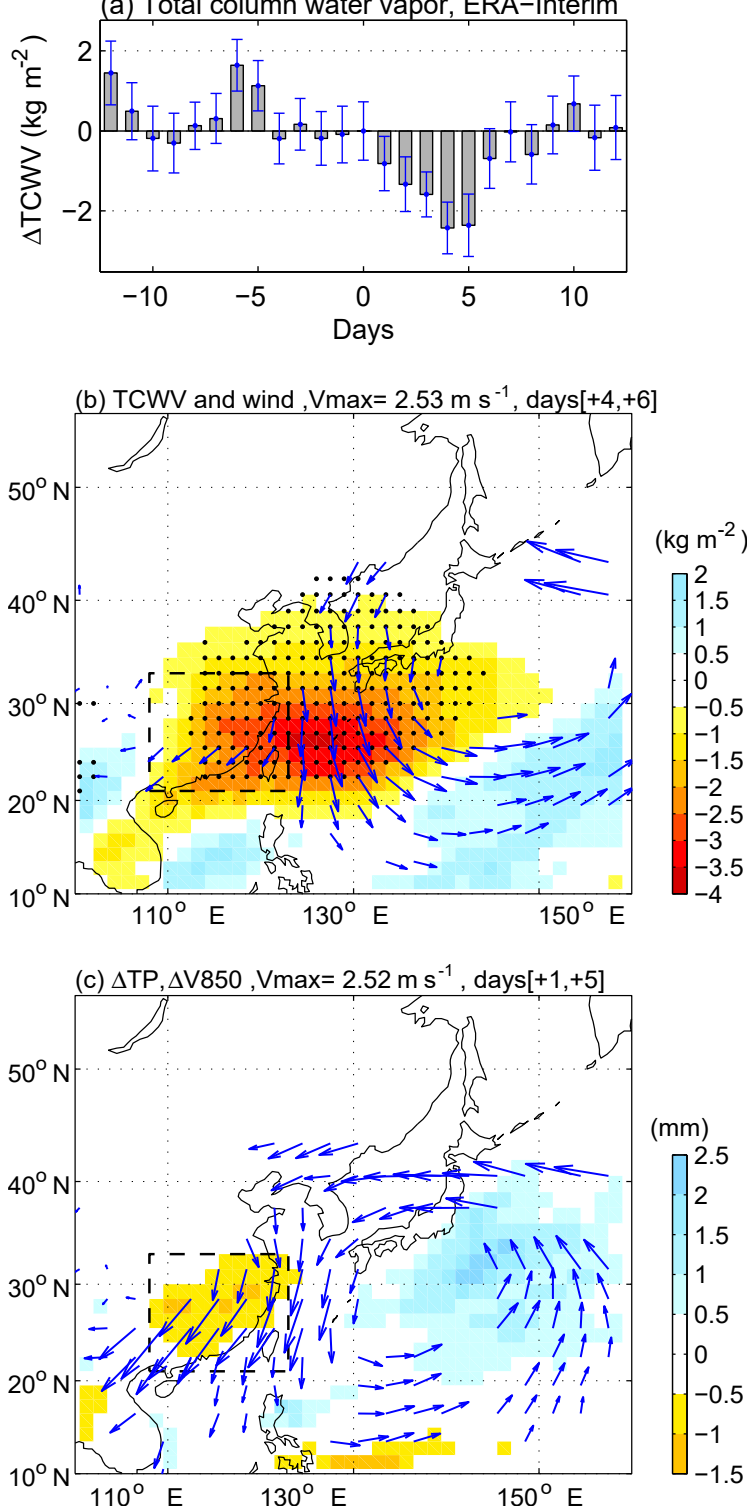

Figure 9. (a) Temporal anomalies of the total column water vapor $(\triangle \mathrm{TCWV})$ during the holiday. (b) Spatial distribution of the $\triangle \mathrm{TCWV}$ (in color shading with units of $\mathrm{kg} \mathrm{m}^{-2}$ ) and the 700 $1000 \mathrm{hPa}$ mean horizontal wind anomalies (in vectors with units of $\mathrm{m} \mathrm{s}^{-1}$ ) during days $[+4,+6]$. Stipples denote significant $\triangle \mathrm{TCWV}$ (at the 0.05 level). Only the anomalous wind vectors significant at the 0.05 level are plotted. (c) Spatial distribution of the mean anomalies of the total precipitation ( $\triangle \mathrm{TP}$; in color shading with units of $\mathrm{mm}$ ) and the significant (at the 0.05 level) $850 \mathrm{hPa}$ mean horizontal wind anomalies (in vectors with units of $\mathrm{ms}^{-1}$ ) during days $[+1,+5]$.

First, we computed the differences between the evaporation and total precipitation (evaporation minus precipitation, i.e., $E-P$ ) using the ERA-Interim data from 00:00 and 12:00 UTC. Note that both evaporation and precipitation are forecasted, and the accumulated variables are collected at step 12 . We analyzed the $E-P$ anomaly (mm, equivalent to $\mathrm{kg} \mathrm{m}^{-2}$ ) during the holiday (figure not shown). From days +1 to +5 , the $E-P$ anomalies are all positive values with a mean of $0.85 \mathrm{~mm}$. In addition, the anomalies on days $+3,+4$, and +5 are all significant at the 0.05 level. The maximum of the $E-P$ anomaly $(+1.25 \mathrm{~mm})$ appears on day +4 . We also investigated the evaporation independently and found it is enhanced during the holiday, with the mean of the evaporation anomalies reaching $+0.39 \mathrm{~mm}$ (figure not shown). Notably, the positive $E-P$ anomalies occur concurrently with the precipitation reductions. The $E-P$ anomalies are likely dominated by precipitation changes. Although the positive $E-P$ anomaly implies a net gain, this effect cannot account for the total net loss of the column water vapor.

Second, we investigated the column water vapor budget contributed by the horizontal transport. Here, we simply estimated the moisture flux across the borders (i.e., the box in Fig. 1). The vertically integrated moisture transport $(Q)$ crossing the border is defined as follows:

$Q=\int_{L}\left[\frac{1}{g} \int_{500 \mathrm{hPa}}^{1000 \mathrm{hPa}} q \cdot \boldsymbol{V} \mathrm{d} p\right] \mathrm{d} l$,

where $\boldsymbol{V}$ is the horizontal wind vector, $g$ is the gravitational acceleration, $q$ is the $\mathrm{SH}$ and $L$ is the length of the border. Moisture transport above $500 \mathrm{hPa}$ is ignored because its contribution to the total column moisture transport is relatively small, and large winds tend to cause errors in the upper troposphere, where the SH is quite small (Qian et al., 2009). Along the northern and southern borders, we computed the meridional transport, while along the eastern and western borders, we computed only the zonal transport. The summation of the meridional and zonal transports yields the net budget. The results show that the net water budgets are negative from day +1 to day +5 (figure not shown), with a mean of $-2.9 \times 10^{7} \mathrm{~kg} \mathrm{~s}^{-1}$. Note that the anomalies of days +1 , +3 , and +4 are all significant at the 0.05 level. The lowest water vapor budget is $-4.4 \times 10^{7} \mathrm{~kg} \mathrm{~s}^{-1}$ (approximately $-1.96 \mathrm{~kg} \mathrm{~m}^{-2} \mathrm{day}^{-1}$ ), occurring on day +4 . This simple calculation suggests that the horizontal moisture transport dominates the anomalous variations in the total net water vapor budget.

Because the negative anomaly in the water vapor budget may be caused by a reduced inflowing water vapor transport or by an increased outflowing transport, we investigated the transport crossing of each of the boundaries during the holiday. We found that the zonal transports crossing the eastern and western borders are negligible (figure not shown). In contrast, the water vapor transport at the southern boundary has the greatest magnitude (Fig. 9). The southern border shows continuous negative anomalies from day +1 to day +5 , and the largest departure of $-5.5 \times 10^{7} \mathrm{~kg} \mathrm{~s}^{-1}$ occurs on day +4 . The anomalies during days +2 to +5 are significant at the 0.05 level and have a mean of $-4.4 \times 10^{7} \mathrm{~kg} \mathrm{~s}^{-1}$. Thus, 
the negative transport crossing the southern border implies an enhanced outflow, and is largely responsible for the net loss of the column water vapor during the holiday.

The water vapor transport over this large area should be closely related to the regional atmospheric circulation. Previous studies have emphasized the importance of anomalous atmospheric circulation over the western Pacific in modulating precipitation over southern China by influencing moisture transport and convergence (e.g., He et al., 2007; Li et al., 2013; among others). To elaborate on the details of the regional atmospheric circulation around the New Year holiday, we investigated the tropospheric horizontal winds over eastern Asia. The vertical mean horizontal winds averaged from 1000 to $700 \mathrm{hPa}$ are plotted in Fig. 9b. Over southeastern China, there are clearly dominant northerly wind anomalies. The northerly winds flow toward the east over the western Pacific, south of approximately $25^{\circ} \mathrm{N}$, and then the winds turn northward. Consistent with this cyclonic circulation anomaly, eastern China and the neighboring western Pacific experience remarkable reductions in the column water vapor. This pattern remains stable when considering each pressure level in the mid-troposphere. For example, at the $850 \mathrm{hPa}$ level, the anomalous cyclone is more evident, and the strong northerly winds over southeastern China are greater than the vertical means (Fig. 9c). Interestingly, the precipitation reduction in southern China is well captured in the ERA-Interim reanalysis, and such reduction is physically consistent with the large-scale atmospheric circulation change. We repeated the composite analysis of the atmospheric circulation using the NCEP/NCAR Reanalysis I and NCEP-DOE Reanalysis II datasets and found a similar pattern (figures not shown). Employing the same ERAInterim data but a shorter data length (2001-2012), Gong et al. (2014) also reported a similarly anomalous circulation pattern over East Asia around the Chinese New Year. This anomalous cyclone is likely a robust signal of the holiday weather. Generally, this anomalous cyclone plays a dominant role in bringing stronger northerly wind, causing less humidity and lower water vapor, which finally results in less precipitation over southeastern China.

\section{Discussion: time-lag correlation between the temperature and anomalous cyclone}

Note that in the observations, the holiday precipitation reduction is strongly related to the significant drying of $\mathrm{SH}$, which is caused by anomalous northerly winds. In fact, an anomalous cyclone dominates East Asia and the western Pacific region during the CSF holiday (Fig. 9). The anomalous northerly winds over southern China are just located in the rear side of the anomalous cyclonic circulation. The anomalous cyclone is likely correlated to the temperature cooling during the CSF holiday. Gong et al. (2014) reported that during days $[-4,0]$, there is no anomalous cyclone over East

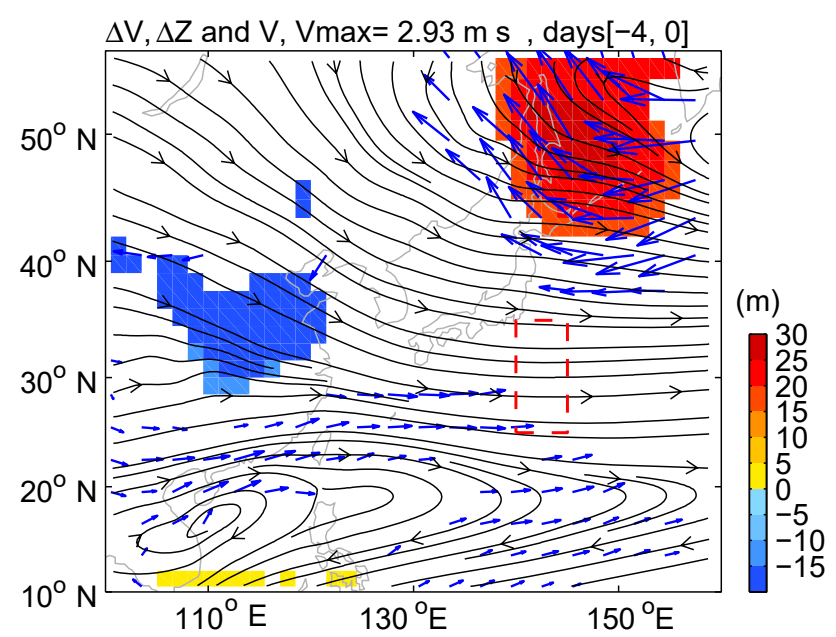

Figure 10. The mean horizontal wind anomalies at $1000-500 \mathrm{hPa}$ (in vectors with units of $\mathrm{ms}^{-1}$ ) and the $1000-500 \mathrm{hPa}$ thickness anomalies (in color shading) during days $[-4,0]$. Only significant (at the 0.1 level) winds and thickness are plotted. The long-term mean horizontal winds between 1000 and $500 \mathrm{hPa}$ during days [ -4 , $0]$ are shown together as the streamlines for comparison. A red dashed rectangle $\left(140-145^{\circ} \mathrm{E}\right.$ and $\left.25-35^{\circ} \mathrm{N}\right)$ indicates the central location of the anomalous cyclone, which is significant on day +5 .

Asia, but simultaneously, the temperature cools significantly. These phenomena can be observed in both the long-term (1979-2012) and short-term (2001-2012) data periods. The anomalous cyclone appears in the troposphere after LNYD, moves eastward, and disappears after approximately 12 days. This result is highly consistent with our analysis, as demonstrated in Fig. 9. On days $[-3,-1]$, the greatest temperature cooling in eastern China was observed (cf., Gong et al., 2014, Fig. 4). As shown in Fig. 10, the lower-middle troposphere shows no evident northerly wind anomaly over East Asia or the western Pacific before LNYD. However, there is significant cooling in the lower-middle troposphere, as indicated by the negative $1000-500 \mathrm{hPa}$ thickness anomalies during days $[-4,0]$. The cooling center is located between $100-130^{\circ} \mathrm{E}$ and $30-40^{\circ} \mathrm{N}$. In this case, the negative temperature anomalies can result in anomalous cold advection due to the climatic northerly winds. This condition is helpful for constructive baroclinic interaction between the upper and lower troposphere and favors the midlatitude cyclone system (Hakim et al., 2003). We would expect a mature cyclone anomaly approximately 1 week later if the cyclone develops from days $[-3,-1]$.

We suppose that the intensity of the cyclone is correlated with the temperature cooling. We computed the time-lag correlation between the holiday cyclone and regional mean temperature. Because the anomalous cyclone is most robust during days $[+4,+6]$, we selected the corresponding center $\left(140-145^{\circ} \mathrm{E}\right.$ and $\left.25-35^{\circ} \mathrm{N}\right)$ to calculate a regional mean for the $500 \mathrm{hPa}$ height. In eastern China, there are 394 available 


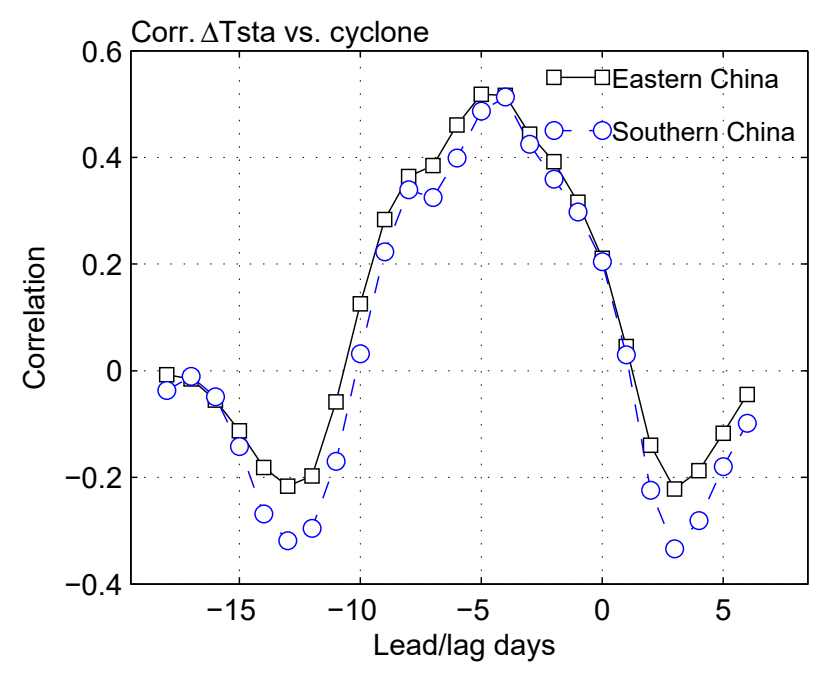

Figure 11. Correlations of the $500 \mathrm{hPa}$ geopotential heights over the anomalous cyclone center $\left(140-145^{\circ} \mathrm{E}\right.$ and $\left.25-35^{\circ} \mathrm{N}\right)$ on day +5 with the regional mean temperature over eastern (southern) China in varying lead or lag days.

meteorological stations. We averaged the daily temperature anomalies of these stations to derive a regional mean time series and then computed the correlation with the $500 \mathrm{hPa}$ height on day +5 . To suppress the noise and identify a stable signal, we used a 3-day window when computing the means, i.e., the data on a specific day as well as those of the day before and after are averaged. The results are plotted in Fig. 11; note that a time-lag of 0 refers to day +5 , a time-lag of -2 refers to day +3 and so on. The results show that the cyclone is closely related to the temperature anomalies that occurred approximately 5 days previously. A maximum correlation of 0.52 is observed when temperature leads the pressure by 4 to 5 days. And it is statistically significant at the 0.1 level. These significant positive correlations suggest that when the temperature is lower around LNYD, the intensity of the anomalous cyclone on days $[+4,+6]$ over the western Pacific is likely to be stronger. Thus, the anomalous cyclone is significantly related to the continental temperature that occurred approximately 1 week previously. The regional temperature over southern China experiences a similar cross-correlation with the following cyclone (Fig. 11). It should be pointed out that these time-lag correlations should not be explained by the natural 1-2 week processes. The natural synoptic system's occurrence and phases are random in time. Here, we prepared the atmospheric circulation and temperature time series according to the lunar calendar dates. If there is a natural cyclone around the CSF holiday, its random phase should be offset by other cyclones when all years are put together. Anyway, these results demonstrate that a stronger cyclone over the western Pacific on days $[+4,+6]$ is often accompanied by lower preceding temperature that occurs approximately 1 week previously over eastern China.
CSF is a cultural event that is only related to human beings. Many studies show that air pollution reduces significantly during the CSF holiday. For example, Tan et al. (2009) investigated the 1994-2006 observations from 13 monitoring sites around the Taipei metropolitan area and found that the concentrations of $\mathrm{NO}_{x}, \mathrm{CO}$, nonmethane hydrocarbon, $\mathrm{SO}_{2}$, and $\mathrm{PM}_{10}$ are lower during the New Year period than during the non-New Year periods. Using three different approaches considering the thermal power generation, satellite retrieval products, and statistical and modeling attribution, Lin and McElroy (2011) estimated that the economic slowdown during the celebrations of CSF is responsible for a notable reduction in anthropogenic emissions. According to their estimations for 2005, 2007, 2008, and 2010, the CSF contributes a $\mathrm{NO}_{x}$ emission reduction of $12 \%$. In addition, the 2009 CSF contributes a reduction of $10 \%$. These estimations are comparable to those given in the work of Gong et al. (2014), in which they reported a $\mathrm{PM}_{10}$ reduction derived from 323 surface station measurements over eastern China and estimated the magnitude of the $\mathrm{PM}_{10}$ concentration decrease to be approximately $-9.24 \%$ for the day -4 to day +5 (excluding day 0 to rule out the New Year's Eve firework emissions). Aerosol is the most likely factor affecting atmospheric physics during the CSF holiday.

In addition, it should be noted that the northerly winds are helpful in cooling the temperature. We think that when considering the simultaneous temperature changes in association with short-period aerosol anomalies, the atmospheric feedback would be ignorable. However, during a moderate period (such as $>3$ days to 1 week), the atmospheric feedback is likely discernible. The mechanism of how the concurrent aerosol reduction influences temperature and further affects circulation needs more elaborate observation and model simulation.

\section{Summary}

Briefly, the major findings of our analysis are summarized as follows.

The long-term station precipitation data from 1979 to 2012 are analyzed with a focus on the possible changes during the CSF holiday. We found that the precipitation frequency over southern China experiences a significant holiday reduction. The largest reduction occurs on days $[+4,+6]$ with a mean anomaly of $-7.4 \%$ and a minimum anomaly of $-9.4 \%$ on day +5 . At the same time, the daily precipitation amounts from day +2 to day +5 show continuous negative anomalies, and the mean is $-0.62 \mathrm{~mm}_{\text {day }^{-1}}{ }^{-}$. The Monte Carlo test implies that the holiday-related frequency and amount anomalies are significantly different from random occurrences. The spatial distributions of the mean frequency anomalies for days $[+4,+6]$ show a clear reduction across southern China. Among the 155 stations, negative anomalies are observed at 148 stations. 
The holiday precipitation anomalies are strongly linked to the relative humidity and cloud cover. The station $\Delta \mathrm{RH}$ shows an evident decrease from day +2 to +7 , and the lowest anomalies appear on days $[+4,+6]$, with a mean of $-3.9 \%$. When all precipitation days are excluded, the $\triangle \mathrm{RH}$ shows similar decreases, where the lowest values also occur on days $[+4,+6]$, with anomalies of $-0.97 \%$, $-0.69 \%$, and $-0.38 \%$, respectively. The $\Delta \mathrm{RH}$ vertical profile demonstrates the significant drying under approximately $800 \mathrm{hPa}$. The ERA-Interim reanalysis data reveal that the negative anomaly at $850 \mathrm{hPa}$ is $-3.9 \%$ and that at $1000 \mathrm{hPa}$ is $-4.2 \%$. The mean $\Delta \mathrm{RH}$ of the layers between 850 and $1000 \mathrm{hPa}$ is $-3.9 \%$. The negative anomalies in the lower troposphere are consistent with the significant decreases in the LCC. The daytime station LCC shows an evident reduction during days $[+4,+6]$, with a mean of $-6.1 \%$. Meanwhile, the daily ERA-Interim LCC also displays a notable reduction during days $[+4,+6]$. The corresponding mean is $-5.0 \%$, and a minimum of $-5.9 \%$ appears on day +5 . This magnitude as well as its spatial distribution is comparable to that of the station-based daytime LCC anomaly.

The anomalous relative humidity is mainly caused by the drying of the water vapor in the lower-middle troposphere over southern China during the holiday. Evident negative SH anomalies persist from days -3 to +7 in the station observations. The lowest values appear on days $[+4,+5]$ approximately. The average $\Delta \mathrm{SH}$ for days $[+4,+6]$ is $-0.73 \mathrm{~g} \mathrm{~kg}^{-1}$. When the precipitation days are excluded, the $\Delta \mathrm{SH}$ shows a similar continuous reduction after LNYD. A minimum of $-0.54 \mathrm{~g} \mathrm{~kg}^{-1}$ appears on day +4 , while the mean for days $[+4,+6]$ is $-0.46 \mathrm{~g} \mathrm{~kg}^{-1}$. Significant water vapor drying is observed for the entire lower troposphere below $700 \mathrm{hPa}$. Below $800 \mathrm{hPa}$, the $\Delta \mathrm{SH}$ values are all less than $-0.50 \mathrm{~g} \mathrm{~kg}^{-1}$. The mean value between 800 and $1000 \mathrm{hPa}$ is $-0.70 \mathrm{~g} \mathrm{~kg}^{-1}$. The water vapor reduction in the lower-middle troposphere likely plays the dominant role in causing anomalous relative humidity, low-level cloud, and precipitation. This water vapor deficit results from the anomalous meridional horizontal moisture transport. During the holiday, a large-scale cyclonic circulation appears over the western Pacific, which brings anomalous northerly winds to East Asia and leads to the negative water vapor flux in the troposphere.

We calculated the correlations between holiday temperature and anomalous cyclone. Cross-correlation demonstrates that approximately 1 week after a lower temperature over eastern China, a stronger cyclone is observed over the western Pacific. The cooling is likely to lead to anomalous cold advection, which provides a favorable condition for the midlatitude cyclone system. The cyclone brings anomalous northerly wind to East Asia, reduces the atmospheric SH, and consequently results in less precipitation over southern China. The mechanisms need further clarification by elaborate observation and numerical modeling.
Data availability. The meteorological data are obtained from the China Meteorological Administration's National Meteorological Information Center (http://data.cma.cn/, last access: August 2017). ERA-Interim reanalysis data used in this study are obtained from ECMWF at http://www.ecmwf.int/, last access: June 2017.

Author contributions. DYG conceived the research. JZ analyzed the data and made the figures. RM, JY, ZZ, and YQ all gave professional guidance. JZ and DYG prepared the manuscript with contributions from all co-authors.

Competing interests. The authors declare that they have no conflict of interest.

Acknowledgements. This research is supported by projects NSFC-41621061, NSFC-40975043, and NSFC-41571039 and is also supported by the State Key Laboratory of Earth Surface Processes and Resource Ecology. Yun Qian's contribution is supported by the US Department of Energy Office of Science Biological and Environmental Research (BER) as part of the Regional and Global Climate Model Analysis Program. PNNL is operated for DOE by Battelle Memorial Institute under contract no. DE-AC05-76RL01830. The comments and suggestions from anonymous reviewers are helpful in improving the manuscript.

Edited by: Aijun Ding

Reviewed by: two anonymous referees

\section{References}

Bäumer, D., Rinke, R., and Vogel, B.: Weekly periodicities of Aerosol Optical Thickness over Central Europe - evidence of an anthropogenic direct aerosol effect, Atmos. Chem. Phys., 8, 83-90, https://doi.org/10.5194/acp-8-83-2008, 2008.

Boucher, O., Randall, D., Artaxo, P., Bretherton, C., Feingold, G., Forster, P., Kerminen, V.-M., Kondo, Y., Liao, H., Lohmann, U., Rasch, P., Satheesh, S. K., Sherwood, S., Stevens, B., and Zhang, X.-Y.: Clouds and Aerosols, in: Climate Change 2013: The Physical Science Basis, Contribution of Working Group I to the Fifth Assessment Report of the Intergovernmental Panel on Climate Change, edited by: Stocker, T. F., Qin, D., Plattner, G.-K., Tignor, M., Allen, S. K., Boschung, J., Nauels, A., Xia, Y., Bex, V., and Midgley, P. M., Cambridge University Press, Cambridge, UK and New York, NY, USA, 571-657, 2013.

Carranza, J. E., Fisher, B. T., Yoder, G. D., and Hahn, D. W.: On-line analysis of ambient air aerosols using laser-induced breakdown spectroscopy, Spectrochim. Acta B, 56, 851-864, https://doi.org/10.1016/S0584-8547(01)00183-5, 2001.

Cerveny, R. S. and Balling, R. C.: Weekly cycles of air pollutants, precipitation and tropical cyclones in the coastal NW Atlantic region, Nature, 394, 561-563, https://doi.org/10.1038/29043, 1998.

Chen, C., Sun, Y. L., Xu, W. Q., Du, W., Zhou, L. B., Han, T. T., Wang, Q. Q., Fu, P. Q., Wang, Z. F., Gao, Z. Q., Zhang, Q., and Worsnop, D. R.: Characteristics and sources of submicron 
aerosols above the urban canopy (260 m) in Beijing, China, during the 2014 APEC summit, Atmos. Chem. Phys., 15, 1287912895, https://doi.org/10.5194/acp-15-12879-2015, 2015.

Dee, D. P., Uppala, S. M., Simmons, A. J., Berrisford, P., Poli, P., Kobayashi, S., Andrae, U., Balmaseda, M. A., Balsamo, G., Bauer, P., Bechtold, P., Beljaars, A. C. M., van de Berg, L., Bidlot, J., Bormann, N., Delsol, C., Dragani, R., Fuentes, M., Geer, A. J., Haimberger, L., Healy, S. B., Hersbach, H., Hólm, E. V., Isaksen, L., Kållberg, P., Köhler, M., Matricardi, M., McNally, A. P., Monge-Sanz, B. M., Morcrette, J.-J., Park, B.-K., Peubey, C., de Rosnay, P., Tavolato, C., Thépaut, J.-N., and Vitart, F.: The ERA-Interim reanalysis: configuration and performance of the data assimilation system, Q. J. Roy. Meteor. Soc., 137, 553-597, https://doi.org/10.1002/qj.828, 2011.

Drewnick, F., Hings, S. S., Curtius, J., Eerdekens, G., and Williams, J.: Measurement of fine particulate and gasphase species during the New Year's fireworks 2005 in Mainz, Germany, Atmos. Environ., 40, 4316-4327, https://doi.org/10.1016/j.atmosenv.2006.03.040, 2006.

Gong, D.-Y., Guo, D., and Ho, C.-H.: Weekend effect in diurnal temperature range in China: Opposite signals between winter and summer, J. Geophys. Res.-Atmos., 111, D18113, https://doi.org/10.1029/2006JD007068, 2006.

Gong, D.-Y., Ho, C.-H., Chen, D., Qian, Y., Choi, Y.-S., and Kim, J.: Weekly cycle of aerosol-meteorology interaction over China, J. Geophys. Res.-Atmos., 112, D22202, https://doi.org/10.1029/2007JD008888, 2007.

Gong, D.-Y., Wang, W., Qian, Y., Bai, W., Guo, Y., and Mao, R.: Observed holiday aerosol reduction and temperature cooling over East Asia, J. Geophys. Res.-Atmos., 119, 6306-6324, https://doi.org/10.1002/2014JD021464, 2014.

Gordon, A. H.: Weekdays warmer than weekends?, Nature, 367, 325-326, https://doi.org/10.1038/367325b0, 1994.

Hakim, G., Joly, A., Ayrault, F., and Malardel, S.: Cyclone, in: Encyclopedia of Atmospheric Sciences, vol. 2, edited by: Holton, J. R., Curry, J. A., and Pyle, J. A., Academic Press, London, 589615, 2003.

He, X., Ding, Y., He, R., He, J., and Li, Q.: Analysis on anomalous precipitation in southern China during winter monsoons, $\mathrm{J}$. Meteorol. Res., 21, 385-396, 2007.

Kim, B.-G., Choi, M.-H., and Ho, C.-H.: Weekly periodicities of meteorological variables and their possible association with aerosols in Korea, Atmos. Environ., 43, 6058-6065, https://doi.org/10.1016/j.atmosenv.2009.08.023, 2009.

Li, B., Gasser, T., Ciais, P., Piao, S., Tao, S., Balkanski, Y., Hauglustaine, D., Boisier, J.-P., Chen, Z., Huang, M., Li, L.Z., Li, Y., Liu, H., Liu, J., Peng, S., Shen, Z., Sun, Z., Wang, R., Wang, T., Yin, G., Yin, Y., Zeng, H., Zeng, Z., and Zhou, F.: The contribution of China's emissions to global climate forcing, Nature, 531, 357361, https://doi.org/10.1038/nature17165, 2016.

Li, H., Lin, Z., and Song, Y.: Analysis of the possible factors that influence March precipitaion anomalies over South China, Chinese J. Atmos. Sci., 37, 719-730, https://doi.org/10.3878/j.issn.10069895.2012.11252, 2013 (in Chinese).

Li, Z., Lau, W. K. M., Ramanathan, V., Wu, G., Ding, Y., Manoj, M. G., Liu, J., Qian, Y., Li, J., Zhou, T., Fan, J., Rosenfeld, D., Ming, Y., Wang, Y., Huang, J., Wang, B., Xu, X., Lee, S. S., Cribb, M., Zhang, F., Yang, X., Zhao, C., Takemura, T., Wang, K., Xia, X., Yin, Y., Zhang, H., Guo, J., Zhai, P. M., Sugi- moto, N., Babu, S. S., and Brasseur, G. P.: Aerosol and monsoon climate interactions over Asia, Rev. Geophys., 54, 866-929, https://doi.org/10.1002/2015RG000500, 2016.

Lin, J.-T. and McElroy, M. B.: Detection from space of a reduction in anthropogenic emissions of nitrogen oxides during the Chinese economic downturn, Atmos. Chem. Phys., 11, 8171-8188, https://doi.org/10.5194/acp-11-8171-2011, 2011.

Murray, F. W.: On the Computation of Saturation Vapor Pressure, J. Appl. Meteorol., 6, 203-204, 1967.

Qian, Y., Gong, D.-Y., Fan, J., Leung, L.R., Bennartz, R., Chen, D., and Wang, W.: Heavy pollution suppresses light rain in China: Observations and modeling, J. Geophys. Res.-Atmos., 114, D00K02, https://doi.org/10.1029/2008JD011575, 2009.

Sanchez-Lorenzo, A., Laux, P., Hendricks Franssen, H.-J., Calbó, J., Vogl, S., Georgoulias, A. K., and Quaas, J.: Assessing largescale weekly cycles in meteorological variables: a review, Atmos. Chem. Phys., 12, 5755-5771, https://doi.org/10.5194/acp12-5755-2012, 2012.

Singh, B. P., Srivastava, A. K., Tiwari, S., Singh, S., Singh, R. K., Bisht, D. S., Lal, D. M., Singh, A. K., Mall, R. K., and Srivastava, M. K.: Radiative Impact of Fireworks at a Tropical Indian Location: A Case Study, Adv. Meteorol., 8, 197072, https://doi.org/10.1155/2014/197072, 2014.

Stjern, C. W.: Weekly cycles in precipitation and other meteorological variables in a polluted region of Europe, Atmos. Chem. Phys., 11, 4095-4104, https://doi.org/10.5194/acp-114095-2011, 2011.

Tan, P.-H., Chou, C., Liang, J.-Y., Chou, C. C. K., and Shiu, C.-J.: Air pollution "holiday effect" resulting from the Chinese New Year, Atmos. Environ., 43, 2114-2124, https://doi.org/10.1016/j.atmosenv.2009.01.037, 2009.

Tang, M., Ji, D.-S., Gao, W. K., Yu, Z.-W., Chen, K., and Cao, W.: Characteristics of air quality in Tianjin during the Spring Festival period of 2015, Atmospheric and Oceanic Science Letters, 9, 1521, https://doi.org/10.1080/16742834.2015.1131948, 2016.

Travis, D. J., Carleton, A. M., and Lauritsen, R. G.: Climatology: Contrails reduce daily temperature range, Nature, 418, 601, https://doi.org/10.1038/418601a, 2002.

Wang, W., Gong, D., Zhou, Z., and Guo, Y.: Robustness of the aerosol weekly cycle over Southeastern China, Atmos. Environ., 61, 409-418, https://doi.org/10.1016/j.atmosenv.2012.07.029, 2012.

Wang, Y., Zhuang, G., Xu, C., and An, Z.: The air pollution caused by the burning of fireworks during the lantern festival in Beijing, Atmos. Environ., 41, 417-431, https://doi.org/10.1016/j.atmosenv.2006.07.043, 2007.

Wang, Z., Li, Y., Chen, T., Li, L., Liu, B., Zhang, D., Sun, F., Wei, Q., Jiang, L., and Pan, L.: Changes in atmospheric composition during 2014 APEC conference in Beijing, J. Geophys. Res.-Atmos., 120, 12695-12707, https://doi.org/10.1002/2015JD023652, 2015.

Wen, W., Cheng, S., Chen, X., Wang, G., Li, S., Wang, X., and Liu, X.: Impact of emission control on $\mathrm{PM}_{2.5}$ and the chemical composition change in Beijing-Tianjin-Hebei during the APEC summit 2014, Environ. Sci. Pollut. R., 23, 4509-4521, https://doi.org/10.1007/s11356-015-5379-5, 2016.

Williams, A. P., Schwartz, R. E., Iacobellis, S., Seager, R., Cook, B. I., Still, C. J., Husak, G., and Michaelsen, J.: Urbanization causes increased cloud-base height and decreased fog in 
coastal southern California, Geophys. Res. Lett., 42, 1527-1536, https://doi.org/10.1002/2015GL063266, 2015.

Xin, J., Wang, Y., Wang, L., Tang, G., Sun, Y., Pan, Y., and Ji, D.: Reductions of $\mathrm{PM}_{2.5}$ in Beijing-Tianjin-Hebei urban agglomerations during the 2008 Olympic Games, Adv. Atmos. Sci., 29, 1330-1342, https://doi.org/10.1007/s00376-012-1227-4, 2012.

Xu, W., Song, W., Zhang, Y., Liu, X., Zhang, L., Zhao, Y., Liu, D., Tang, A., Yang, D., Wang, D., Wen, Z., Pan, Y., Fowler, D., Collett Jr., J. L., Erisman, J. W., Goulding, K., Li, Y., and Zhang, F.: Air quality improvement in a megacity: implications from 2015 Beijing Parade Blue pollution control actions, Atmos. Chem. Phys., 17, 31-46, https://doi.org/10.5194/acp-17-31-2017, 2017.

Xu, W. Q., Sun, Y. L., Chen, C., Du, W., Han, T. T., Wang, Q. Q., Fu, P. Q., Wang, Z. F., Zhao, X. J., Zhou, L. B., Ji, D. S., Wang, P. C., and Worsnop, D. R.: Aerosol composition, oxidation properties, and sources in Beijing: results from the 2014 Asia-Pacific Economic Cooperation summit study, Atmos. Chem. Phys., 15, 13681-13698, https://doi.org/10.5194/acp-1513681-2015, 2015.
Yang, X., Li, Z., Liu, L., Zhou, L., Cribb, M., and Zhang, F.: Distinct weekly cycles of thunderstorms and a potential connection with aerosol type in China, Geophys. Res. Lett., 43, 8760-8768, https://doi.org/10.1002/2016GL070375, 2016.

Zhang, M., Wang, X., Chen, J., Cheng, T., Wang, T., Yang, X., Gong, Y., Geng, F., and Chen, C.: Physical characterization of aerosol particles during the Chinese New Year's firework events, Atmos. Environ., 44, 5191-5198, https://doi.org/10.1016/j.atmosenv.2010.08.048, 2010.

Zhao, C., Tie, X., and Lin, Y.: A possible positive feedback of reduction of precipitation and increase in aerosols over eastern central China, Geophys. Res. Lett., 33, L11814, https://doi.org/10.1029/2006GL025959, 2006. 